\title{
7. Alltagskulturen und Identitäten
}

\author{
Christel Baltes-Löhr, Agnes Prüm, Rachel Reckinger, \\ Christian Wille
}

\subsection{Einleitung und Fragestellung}

Der Schwerpunkt dieses Beitrags liegt auf der empirischen Analyse von Interaktionen im sozialen Alltag. Unsere gemeinsamen Forschungsfragen lauten dabei: Wie werden alltagskulturelle Identitäten im Spannungsfeld zwischen zugeschriebenen und angeeigneten Identitäten ausgehandelt? Wie und warum artikuliert sich diese identitäre Wechselbeziehung in der Alltagspraxis? Welche Erklärungen, Legitimierungen und Interpretationen für Handeln und Einstellungen werden gegeben? Diese Fragestellungen werden von Forschern/-innen aus unterschiedlichen disziplinären Blickwinkeln anhand der Bereiche Geschlechterwahrnehmungen, >banale< Konsumformen und soziale Ordnungen beleuchtet.

Die im Folgenden diskurspraktisch (s.u.) erschlossene Alltagspraxis konstituiert sich aus kollektiv geteilten Werten, Einstellungen und Normen (>Conceptas $<$ ), sowie aus Formen des Wahrnehmens, Glaubens, Bewertens und Handelns, wie sie sich in der sozialen Interaktion manifestieren (>Perceptas $<$ ). (Bolten 2007) Dabei schwingt in den unten vorgestellten Ergebnissen stets das Kollektive im Individuellen und das Individuelle im Kollektiven mit, was nicht zuletzt eine Veränderbarkeit und Vielschichtigkeit der untersuchten Identitäten einräumt. Diese Grundlegung des Identitätsbegriffs verweist zunächst auf seine Pluridimensionalität, welche Individuen nicht auf feste Kategorien (z.B. Frau/Mann) reduziert, sondern ebenso kontextuelle und intersektionale Zugehörigkeiten (z.B. sozio-kulturelle Milieus, Altersgruppen, Affinitätsgruppen usw.) berücksichtigt.

\section{Alltagskulturen in praxeologischer Perspektive}

Die folgenden Untersuchungen fokussieren somit nicht auf vorgefertigte kognitive Bedeutungs- und Sinnstrukturen von >alltäglicher Kultur<, sondern auf ihren praktischen Einsatz - wobei es nicht darum geht, was Menschen jeden Tag tun, sondern welche Selbstverständlichkeiten und Irritationen in den Einstellungen und im Handeln von den Subjekten geteilt werden. Denn es wird davon ausge- 
gangen, dass Kultur ihren Ausdruck in der konkreten Auseinandersetzung mit der dinglichen und sozialen Umwelt findet: »Kultur lässt sich [...] erst im Umgang mit Dingen und Körpern wirklich >dingfest<, d.h. sichtbar, aufzeigbar, nachweisbar, nachvollziehbar machen.« (Hörning/Reuter 2004: 12) Angesprochen werden damit Praxiszusammenhänge, in denen sich das Kulturelle artikuliert. Hier sind besonders Formen des Zwischenkategorialen wie etwa »Third Spaces« (Bhabha 2000) bedeutsam, die unter dem Stichwort der Ambivalenz erläutert werden. Das skizzierte Kulturverständnis wird im Folgenden unter dem Begriff >Alltagskulturen< gefasst, wobei der hier wiederum gewählte Plural die Aufmerksamkeit auf parallel verlaufende und unterschiedliche Prozesse sozialer Interaktion und deren Effekte lenken soll.

Der erste Aspekt dieses Doppelbegriffs unterstreicht die Lebensnähe unseres Ansatzes, der sich auf unhinterfragte, »vertraute Selbstverständlichkeiten, eingelebtes Alltagswissen und routinisiertes Alltagshandeln« (Hillmann 2007: 19) konzentriert. Routinen, Rituale und Ausgestaltungen sind hierbei nicht als mechanische, starre Wiederholungen von alltäglichen Einstellungen und Handlungsabläufen, sondern als permanente, geringfügige Verschiebungen im Sinne eines Wandels aufzufassen (Butler 1993; Deleuze 1968), die Derrida mit dem Konzept der >différance< beschreibt (Derrida 1968). Die hier angesprochenen Verschiebungen lassen einen individuellen Handlungsspielraum zu, stellen die Intersubjektivität in Handlungssituationen aber nicht infrage. Kollektive Wissensbestände können unsystematisch, wertend und teilweise widersprüchlich sein (Schütz 1972), d.h. eine pragmatische Vereinfachung von alltäglichen Handlungen darstellen - womit sie eine gewisse interpretative Offenheit mit einer normativen Regelhaftigkeit verbinden. Trotz der intersubjektiven Konsensfähigkeit von Alltagswissen »machen sich infolge sozialstruktureller, gruppenspezifischer und biographischer Einflüsse individuelle Differenzierungen [...] bemerkbar« (Hillmann 2007: 20), welche wiederum auf das Alltagswissen zurückwirken.

Der zweite Aspekt des Begriffs >Alltagskulturen< schließt an die kulturtheoretische Debatte an. Wie oben angedeutet, geht es hier nicht um ein normatives oder holistisches Begriffsverständnis von Kultur, vielmehr steht das wissens- und bedeutungsorientierte Kulturverständnis im Vordergrund (Reckwitz 2001; Reckwitz 2004). Dieses geht davon aus, dass vor dem Hintergrund der symbolischen Ordnungen der sozialen Welt unterschiedliche Verhaltenskomplexe entstehen, reproduziert und verändert werden und die Ebene des Kulturellen bilden. Dieser Kulturbegriff wird in den Sozial- und Kulturwissenschaften fortwährend angepasst und weiterentwickelt, wobei sich die Frage stellt, ob Kultur als eine Konfiguration von übersubjektiven symbolischen Strukturen oder als Ergebnis subjektiv-interpretativer Leistungen aufzufassen ist. Dieser Fragestellung kann mit einer praxeologischen Synthese beider Perspektiven begegnet werden. Während die strukturalistische Sicht hilft, Kultur als übersubjektive Zuschreibung aufzudecken, verengt diese Perspektive den Blick auf Phänomene des kulturellen Wandels oder der subjektiven Aneignung. Hier greift die Konzeptualisierung von Kultur als Ergebnis 
subjektiver Interpretationsleistung, etwa wenn die alltagskulturellen und innovativen Aneignungen der Subjekte untersucht werden. Diese erfolgen jedoch nicht losgelöst von sozio-kulturellen Bedingungen und Ressourcen, die den handelnden Subjekten - durch ihre verschiedenen, jedoch eingeschränkten Positionen im sozialen Raum - zur Verfügung stehen, wie es die Praxeologie impliziert. (Bourdieu 2000 [1972]; Bourdieu 1980)

Dieser Beitrag folgt dem skizzierten > praxeologischen Synthesemodell < und betrachtet Prozesse der identitären Zuschreibung im dargelegten strukturalistischen Sinn und die Aneignungsprozesse bzw. -praktiken als interpretative Leistungen der Subjekte. Über die Zusammenführung beider Perspektiven kann der Dualismus von Kultur als Struktur einerseits und Kultur als subjektive Leistung andererseits überwunden werden, indem phänomenologisch und strukturalistisch orientierte Ansätze theoretisch und empirisch miteinander verknüpft werden. Das bedeutet, hier werden die sozialstrukturellen Einbettungen im sozialen Raum gleichzeitig mit den subjektiven Einstellungen und Handlungen der Akteure gedacht. In diesem Sinne repräsentiert eine Praktik - sei es als Zuschreibung bzw. Aneignung von Genderkonzepten, Konsumformen oder gesellschaftlicher Ordnungskategorien einen Komplex von diskurspraktisch vollzogenen (s.u.), sinnhaften und wandelbaren Verhaltensroutinen, die durch eine implizite >Logik des Alltags < zusammengehalten werden. Die Arbeitsgruppe versucht solche alltagskulturellen Logiken aufzudecken und knüpft hierfür an die Praktiken der sozio-kulturellen Milieus der Luxemburger Wohnbevölkerung an.

\section{Konstruktionen von Identitäten als soziale Praxis}

Die alltagskulturelle Identitätsarbeit in den untersuchten Bereichen charakterisiert sich durch eine gewisse >Unsichtbarkeit<, da sie in der Alltagspraxis i.d.R. nicht hinterfragt wird und der Pragmatik des konkreten Handelns unterliegt. Erst die Befragungssituation führt zu einer reflektierten Verbalisierung bzgl. der betreffenden Thematik. ${ }^{1}$ Sie ermöglicht Einblicke in subjektive und in den Interviewinteraktionen artikulierte Sinnwelten. Sowohl dieser diskursive Akt als auch seine Bedeutungsinhalte werden mit Foucault als > Diskurspraktiken< aufgefasst:

Es handelt sich darum, die diskursiven Praktiken in ihrer Komplexität und in ihrer Dichte erscheinen zu lassen, zu zeigen, dass Sprechen etwas tun heißt - etwas anderes, als das auszudrücken, was man denkt, das zu übersetzen, was man weiß, etwas anderes auch, als die Strukturen einer Sprache spielen zu lassen; zu zeigen, dass eine Aussage einer bereits vorher existierenden Folge von Aussagen hinzuzufügen heißt, eine komplizierte und kostspielige Geste zu tun, die Bedingungen impliziert (und nicht nur eine Situation, einen Kontext, Motive) und die Regeln umfasst (die von den logischen und sprachlichen Konst-

1 | Dies bedeutet nicht, dass im Alltag nicht reflektiert wird, sondern vielmehr dass alltagskulturelle Entscheidungen während ihrer Umsetzung kaum hinterfragt werden. 
ruktionsregeln verschieden sind); zu zeigen, dass eine Veränderung in der Ordnung des Diskurses nicht 'neue Ideen`, ein wenig Erfindungskraft und Kreativität, eine andere Mentalität, sondern Transformationen in eine Praxis [...] voraussetzt. (Foucault 1969: 297-298; )

Dies bedeutet einerseits, dass unterschiedliche Diskurse sich wechselseitig beeinflussen und andererseits, dass ihre Interaktionen performativ sind, so dass die Personen - in unserem Fall die Befragten - »etwas mit den Worten tun « (Austin 1970). Jedoch >tun< ebenso die Worte etwas mit ihnen. Dieses Ineinandergreifen bringt >Diskurspraktik < auf den Begriff und verdeutlicht, dass Diskurse die Praktiken strukturieren (Diskursivität der Praktiken) und gleichzeitig Praktiken die Diskurse strukturieren (Performativität der Diskurse). (Reckinger 2008) Diese Sichtweise hilft, Diskurse und Praktiken nicht als autonome, sozio-kulturell freischwebende Gebilde zu betrachten, sondern den Blick auf ihre konstruierte Relation zu lenken.

In diesem Sinn ist aus methodischer Sicht zu hinterfragen, inwiefern soziale Praktiken mit empirischen Erhebungstechniken erfasst werden können. Grundsätzlich ist dabei zwischen Verfahren zu unterscheiden, mit denen soziale Praktiken mittelbar bzw. unmittelbar zugänglich werden. Zu Letzteren zählen z.B. teilnehmende Beobachtungen oder experimentelle Verfahren, welche kontrollierte Rahmenbedingungen und damit eine Alltagsferne für die Befragten implizieren. Hingegen wird mit Befragungen, Interviews oder Inhaltsanalysen ein mittelbarer Zugriff möglich, der den verbalen Zugang privilegiert und daher für unsere Zwecke geeigneter ist. So war es z.B. in qualitativen Interviews und quantitativen Befragungen möglich, mit den handelnden oder an sozialen Praktiken beteiligten Subjekten in Kontakt zu treten und über ihre Bekundungen bestimmte Informationen über soziale Praktiken, ihre Regelmäßigkeit und Häufigkeit sowie über ihre subjektiven Bedeutungen zu erhalten. Ferner bietet die diskurspraktische Inhaltsanalyse die Möglichkeit, verschiedene Handlungsaspekte zu rekonstruieren, wobei sie nicht auf die Handlungen selbst fokussiert, sondern auf ihre Performativitäten. Dabei geht es hier um die Analyse von Gesetzestexten, Informationsmaterialien und statistischen Daten mit dem Ziel, Spuren sozialer Praktiken aufzudecken und Rückschlüsse auf >Logiken des Alltags < zu ziehen.

Neben dem erläuterten methodischen Aspekt gilt es, weiterführende Überlegungen hinsichtlich der betrachteten Identitäten bzw. Differenzsetzungen durch die Subjekte vorzunehmen. (Reuter/Wiesner 2008) Die Beschäftigung mit diesen Kategorien ist im Zuge von Globalisierung und Liberalisierung vielschichtiger geworden. Formen der Hybridisierung oder Bindestrichkonstruktionen stellen klassische Theorieangebote auf den Prüfstand und unterlaufen binäre Differenzvorstellungen und Ordnungskategorien. So werden die theoretischen Figuren des Zwischenkategorialen (Reuter/Wiesner 2008) im Rahmen poststrukturalistischer und postmoderner Ansätze zunehmend als ambivalente Gegenwartsphänomene (wieder-)entdeckt. Ihnen gemeinsam ist das Aufbrechen der binären Logiken von weiblich/männlich, gut/schlecht, fremd/vertraut usw., die im Allgemeinen als Er- 
klärungskategorien herangezogen werden. Konzepte des Zwischenkategorialen (Bhabha 2000; Welsch 2005; Breinig/Lösch 2006) versuchen die Durchdringung von vorgängig gesetzten Differenzen zu erfassen und lenken das Augenmerk auf »prozesshafte, dynamische, flüssige Vermischungen, die sich nicht ohne weiteres feststellen lassen « (Reuter/Wiesner 2008: 132). Der so umschriebene ambivalente Zustand des Dazwischen, welcher sich gegen klare Zuordnungen sperrt, erfindet sich permanent neu.

Das Forschungsinteresse der Arbeitsgruppe richtet sich u.a. auf solche flüchtigen Momente der Ambivalenz auf der Ebene des Alltagskulturellen. Sie geht davon aus, dass die Binarität von Differenzen im Rahmen sozialer Praktiken aufgebrochen werden kann und einer >Logik des Alltags < folgend sich innovativ rekonfiguriert. Somit geht es nicht um die Auflösung von Differenzen, sondern um die alltagskulturelle Überschreitung von binären Kategorien. Der Blick verschiebt sich somit von der binär codierten Logik des »Entweder-oder « zur ambivalenten Logik des »Sowohl-als-auch« (vgl. Baltes-Löhr 2006: 70) als ein weitgehend vernachlässigter Aspekt alltagskultureller Praktiken. Diese Verschiebung soll nicht als Ersetzung, sondern als Erweiterung gedacht werden, da auf phänomenologischer Ebene sowohl die Rekonstruktion von Binaritäten als auch ihre Überschreitung und Neukonfiguration auszumachen ist.

Vor diesem Hintergrund werden im Folgenden in den alltagskulturellen Bereichen der Geschlechterwahrnehmung, Konsumformen und Aneignung von sozialen Ordnungen beispielhaft verschiedene Momente der Ambivalenz und die damit verknüpften Dynamiken von Identitätskonstruktionen betrachtet. Zunächst werden Wirkmächtigkeiten von Geschlechterbildern eruiert und nach der Virulenz von Geschlecht bei in Luxemburg lebenden Frauen und Männern gefragt. Hegemonial wirksame Zuschreibungsprozesse im Kontext der Konstruktionen von Geschlechteridentitäten werden ebenso betrachtet wie individuelle Aneignungsprozesse in ihren unterschiedlichen Äußerungsformen. Hierzu werden homogenisierende bzw. differenzierende Vorstellungen von Geschlechteridentitäten vor einer intersektionalen Folie beleuchtet und der Relevanz der Dichotomie »konstruktivistische vs. essentialistische Geschlechterbilder« nachgegangen. Neben der Frage nach der Bedeutung der Geschlechterzugehörigkeit im Umgang mit anderen Menschen werden Favorisierungen unterschiedlicher Modelle zur Vereinbarkeit von Beruf und Privatleben in Bezug zueinander und den jeweiligen Milieus vorgestellt. Quer hierzu wird die kategoriale Trennschärfe von Geschlecht als Analysekategorie hinsichtlich alltagskultureller Genderthematiken in ihrer Verschränkung zwischen Zuschreibungs- und Aneignungsprozessen überprüft.

Des Weiteren wird die Norm und das Verständnis von >gutem< Essen zwischen politischem Leitbild und individueller Alltagspraxis thematisiert. Die Analyse konzentriert sich in einem ersten Schritt auf ein zuschreibendes politisches Handlungskonzept, das Gesundheitsorientierung - kreativ, aber objektbezogen - in seinen Empfehlungen zu vermitteln sucht. Anschließend wird der Schwerpunkt auf alltägliche Ernährungspraxen gelegt, deren Aneignungsformen um Eigen- 
verantwortung, Handlungspotential und hedonistischen Pragmatismus - in eher personenbezogener Perspektive - kreisen. Die dynamischen Wechselwirkungen zwischen diesen beiden Interpretationstypen von >gutem< Essen eröffnen kontextgebundene Spielräume für Identitätskonstruktionen.

Schließlich sollen am Beispiel des Grenzgängerwesens in Luxemburg Aussagen über Prozesse der Identitätskonstruktion getroffen werden. Dabei steht die Wahrnehmung der grenzüberschreitenden Pendler/-innen durch die Luxemburger Wohnbevölkerung im Vordergrund, die hier verschiedene Formen der Konstruktion dieses Phänomens aufzeigt. In diesem Sinne sollen Identitätsaneignungen bzw. Positionierungen der Luxemburger Wohnbevölkerung gegenüber dem Grenzgängerwesen nachgespürt werden. Hierfür werden alltagskulturelle Einund Ausschlussstrategien beleuchtet und darauf aufbauend der Status des Grenzgängers im Großherzogtum bestimmt. In einem zweiten Schritt wird der Frage nachgegangen, welche Rückschlüsse die aufgedeckten und teilweise ambivalenten Aneignungen auf Prozesse der Identitätsbildung zulassen.

\subsection{Permanente Performanzen: gender in motion}

In diesem Teil der Untersuchung werden Wirkmächtigkeiten von Geschlechterbildern eruiert. Welche Repräsentationen von Geschlecht sind bei in Luxemburg lebenden Frauen und Männern virulent? Ausgehend von Zuschreibungsprozessen von Geschlechteridentitäten via hegemoniale Geschlechterdiskurse richtet sich der Blick der Untersuchung vor allem auf Prozesse der Aneignungen von Geschlechteridentitäten und Geschlechterbildern im intersektionalen Kontext. Hiermit verbunden sind zwei forschungsleitende Aspekte: einmal die Frage, inwieweit dualistisch konnotierte Unterscheidungen zwischen essentialistischen und konstruktivistischen Geschlechterbildern im empirischen Material abgebildet sind, und zum anderen die Frage nach der Trennschärfe von Geschlecht als Analysekategorie. Inwieweit kommt also der Kategorie >Geschlecht< hinsichtlich des Antwortverhaltens der Befragten eine signifikante Bedeutung zu?

Im Rahmen einer repräsentativen Studie und 27 leitfadengestützten Interviews wurden die Vorstellungen zu Weiblichkeiten, Männlichkeiten sowie zu Homo- und Transsexualität und die Bedeutung der Kategorie >Geschlecht< für den Umgang mit anderen ebenso ermittelt wie Einschätzungen hinsichtlich der in Luxemburg existierenden Gleichstellung bzw. Diskriminierungen der Geschlechter. Daneben ging es um die von den Befragten favorisierten Gendermodelle mit Blick auf eine verbesserte Vereinbarkeit von Beruf und Privatleben und nicht zuletzt um Kenntnisse zu nationalen Gesetzen und Kampagnen rund um die Thematik >Gender ${ }^{2}$.

2 | Hierzu wurden begleitend zu diesem Forschungsprojekt die seit Ende der 1960er Jahre in Luxemburg zum Thema ,Gleichberechtigung/Gleichstellung der Geschlechter, verabschiedeten Gesetzestexte gesichtet und analysiert. Die Ergebnisse dieser Doku- 
Die folgende Darstellung bezieht sich somit auf die Auswertung von vier statistischen Itembatterien mit insgesamt 22 Items sowie 290 Interviewsequenzen aus 27 Interviews mit Frauen und Männern.

\section{Theoretische Rahmung}

Identitäten und damit auch Geschlechtsidentitäten werden als pluridimensionale, intersektionale Repräsentationskonstruktionen betrachtet. (Vgl. McCall, 2005; Hirschauer, 2001; Klinger/Knapp 2005; Baltes-Löhr 2006: 66) Neben der Geschlechterkategorie, die lange Zeit als die gesellschaftliche Strukturkategorie betrachtet wurde, und dem körperbezogenen biologischen Geschlecht >sex< treten auch ethnische und sozio-ökonomische Aspekte ebenso wie Alter in den Vordergrund, wenn es um Konstruktionen von Identitäten geht. ${ }^{3}$ Unabhängig von der Anzahl der > Sektionen < wird die Bedeutung der Kategorie > Geschlecht< durch ihre intersektionale Kontextualisierung entdramatisiert.

Neben ihrer intersektionalen Verfasstheit sind Identitäten als Momentaufnahmen von ständig sich in Bewegung befindlichen und sich verändernden performativen Konstruktionsprozessen zu betrachten. Trotz aller Fluidität und Veränderbarkeit scheinen bestimmte identitäre Aspekte sich eher zu verflüchtigen, während andere sich sedimentieren, sei es im hegemonialen Diskurs und/oder der alltagsweltlichen individuellen Praxis. Performative Konstruktionsprozesse, performative Handlungen (Butler 1993: 123) rufen durch Benennungen und Inszenierungen sowie durch wiederholte Darbietungen in Zeit und Raum ihren Gegenstand, also auch Identitäten, hervor. In solchen sich wiederholenden performativen Handlungen liegen Möglichkeiten für Verfestigungen des Wiederholten sowie zum diskursiven Durchbrechen vorherrschender Bilder und damit zur Vervielfältigung binärer Muster, in dem z.B. andere Facetten von Geschlechtsidentitäten hervorgebracht werden.

Bergen Wiederholungen Möglichkeiten, vielfältige Aspekte eines Gegenstandes präsent werden zu lassen, so dass sich dualisierende Hierarchien verändern, verschieben und auflösen können, dann ist die Wirksamkeit von Wiederholung als enthomogenisierend und heterogenisierend $\mathrm{zu}$ beschreiben. Differenzen wird Raum gegeben. Gleichzeitig können Ähnlichkeiten erkennbar und vertieft werden. Neues entsteht somit immer in Bezug auf etwas, meist das Alte, das

mentenanalyse sind in einer eigenen Veröffentlichung zusammengefasst und werden hier nur kursorisch behandelt. Baltes-Löhr, Christel/Stricker, Susanne: Eine Untersuchung der luxemburgischen Gesetzgebung in Bezug zur Konvention CEDAW und dem ihr implizierten Gleichstellungsprinzip, Universität Luxemburg 2009.

3 | Es gibt unterschiedliche Vorstellungen darüber, welche randeren، Kategorien hinsichtlich der Identitätskonstruktionen bedeutsam sind. Knapp (2005) fügt race، und 'classı hinzu. Lutz/Wenning (2001) finden 13 Differenzkategorien, betonen jedoch die Unvollständigkeit der Liste. McCall (2005) spricht von 'gender, ,race‘, 'class` und fügt die Kategorie region، hinzu; Baltes-Löhr (2009) die Kategorie ‘körperliche Verfasstheit. 
Tradierte, das Bekannte. Das Neue entsteht in langsam sich verschiebenden Veränderungen.

Ebenso wie kultureller Pluralismus und kulturelle Differenzen nicht nur zwischen den Kulturen, sondern auch innerhalb der Kulturen zu verorten sind, (Kumoll 2006: 86) kann dies auch für Identitätskonstruktionen vermutet werden. Es gilt, das Minoritär-werden (Deleuze nach Rölli 2006: 39) als differentielle Regel zu begreifen, d.h., dass faktisch vorliegende Merkmale, anhand derer beispielsweise kulturelle Zugehörigkeiten identifiziert werden, als Effekte einer ihnen vorausgehenden Sinnzuschreibung betrachtet werden. Solche Vorstellungen von Minoritär-werden grenzen sich ab gegen Annahmen von essentialistisch konnotiertem Anders-Sein bzw. Nicht-identisch-sein. Hegemoniale Identitätszuschreibungen können somit demontiert bzw. dekonstruiert werden, wenn die Prozesse des Minoritär-werdens hervorgehoben werden, so dass etablierte, selbstverständlich oder gar natürlich anmutende Strukturen der Mehrheit, und damit - im foucaultschen Sinne - oftmals der Macht, als bedingt und damit veränderbar erscheinen können. (Rölli 2006: 40)

Ähnlich wie bei differenten kulturellen Repräsentationen sind besonders die Zwischenräume oder >Third Spaces< (Rutherford 1990: 207-221; Chambers 1996: 78; Gregory 1997: 228) für Artikulationen identitärer Minoritäten oder Minderheitenpositionen bedeutsam. Sind mit Bhabha »Kulturen zwar durch das Begehren nach Stabilität und Determination, beispielsweise im Sinne einer Nation, gekennzeichnet [...], müssen aber gerade in der Instabilität, der Gleichzeitigkeit von inkommensurablen Geschichten (Narrativen und Historizitäten) und Orten gedacht werden« (Bhabha nach Bonz/Struve 2006: 141), dann lässt sich dies ebenfalls auf die Konstruktionsprozesse von Identitäten übertragen. Identitätskonstruktionen werden durch ihre Differenziertheit charakterisiert. Identitäten werden zu einem Ort der Aushandlung und der Äußerung. Identitäten und identitäre Subjekte fallen jedoch nicht ineinander, sondern können different sein. Scheinbar homogenen Identitäten wohnen somit identitäre Differenzen inne. So wie Bhabha gegen eine multikulturell orientierte kulturelle Vielfalt und für eine kulturelle Differenz plädiert, die den kulturellen Antagonismen, Widersprüchlichkeiten und Inkommensuralibilitäten gerecht wird (Bonz/Struve 2006: 149), kann die Annahme identitärer Differenzen (konstruktivistischer Ansatz) den tatsächlich gelebten und wahrgenommenen Widersprüchlichkeiten, Gegensätzen eher gerecht werden, als das Suchen und Streben nach homogenen, identitären Identitäten (essentialistischer Ansatz).

Im Folgenden wird also zu zeigen sein,

- welche homogenisierenden bzw. differenzierenden Vorstellungen von Geschlechteridentitäten zusammen mit anderen intersektionalen Komponenten erkennbar sind;

- welche Relevanz der Dichotomie >konstruktivistisch vs. essentialistisch< zukommt;

- welche Bedeutung dem Geschlecht im Umgang mit anderen Menschen zugewiesen wird und wie mit Anderssein und anderen umgegangen wird; 
- welche Modelle zur Vereinbarkeit von Beruf und Privatleben favorisiert werden;

- welche konkreten Kenntnisse in Bezug auf Maßnahmen und Gesetze zur Gleichstellung von Frauen und Männern bekannt sind.

\section{Resistente Reste. Wie stark wirken essentialistische Geschlechterbilder heute noch?}

Aus der repräsentativen Studie geht hervor, dass $90 \%$ der Befragten der Annahme einer natürlich gegebenen Unterschiedlichkeit zwischen Frauen und Männern zustimmen. Gleichzeitig gehen $77 \%$ davon aus, dass weibliches bzw. männliches Verhalten im Laufe des Lebens erlernt wird. $96 \%$ aller Befragten betonen, dass Frauen ebenso wie Männer geeignet sind, gesellschaftliche Leitungsfunktionen zu übernehmen. Hier deutet sich an, dass die oftmals aufgerufene und vertiefte Divergenz zwischen Essentialismus und Konstruktivismus nicht in der zu vermutenden dichotomen Binarität besteht, sondern beide Haltungen miteinander einhergehen können.

Die deutlich hohe Zustimmung zu der Annahme geschlechtsunabhängiger Befähigungen hinsichtlich der Übernahme von Führungspositionen geht einher mit dem Ergebnis, dass lediglich 56 \% äußern, dass die vermeintlich gleichen Möglichkeiten im beruflichen Feld von Frauen und Männern in Luxemburg auch tatsächlich gleichermaßen genutzt werden. Dies deutet darauf hin, dass eine faktische Geschlechterdisparität auf dem luxemburgischen Arbeitsmarkt immer noch als ein gewichtiger Faktor der Diskriminierung zwischen Frauen und Männern zu gelten scheint. Dies wird auch durch die Aussagen aus den Interviews bestätigt: dort wird Geschlechterdiskriminierung vor allem in der Unterrepräsentanz von Frauen in Leitungspositionen und der ungleichen Bezahlung gesehen.

Interessante Ergebnisse zeigen sich hinsichtlich des Antwortverhaltens von Frauen und Männern. Die natürliche Unterschiedlichkeit zwischen den Geschlechtern wird signifikant häufiger von Männern angenommen, was auf eine eher essentialistische Haltung hindeutet. Dieser Zusammenhang zeigte sich für Luxemburg erstmals in einer Untersuchung zur »Bedeutung des Geschlechteraspektes für die berufliche und persönliche Entwicklung/Biographie von zukünftigen Erziehenden und Lehrenden «4 (Baltes-Löhr et al. 2005: 87).

In der vorliegenden Untersuchung stimmen signifikant mehr Frauen als Männer der Annahme zu, dass beide Geschlechter gleichermaßen geeignet seien, leitende Funktionen in der Gesellschaft einzunehmen. Demgegenüber sind sig-

4 | Im März-April 2003 durchgeführte Vollerhebung bei Studierenden bzw. Schülerinnen und Schülern des damaligen ISERP (Institut Supérieur d'Etudes et de Recherches Pédagogiques), der Referendariatsausbildung für das Lehramt in der Sekundarstufe am CUNLUX (Centre Universitaire de Luxembourg) und dem damaligen IEES (Institut d'Etudes Educatives et Sociales) mit der Ausbildung und den Studien zur Erzieherin/zum Erzieher und zur Sozialpädagogin/zum Sozialpädagogen (Educatrice graduée/Educateur gradué). 
nifikant weniger Frauen der Ansicht, dass beide Geschlechter berufliche Aufstiegschancen in gleichem Maße nutzen. Dem entspricht, dass deutlich mehr Frauen sich bereit erklären, beruflich kürzer zu treten, um Beruf und Familie besser vereinbaren zu können. Auch hier lohnt sich wiederum ein Blick auf die Ergebnisse der o.g. Studie, dass nämlich »bei tatsächlich stattgefundenen Einstellungsveränderungen scheinbare Resistenzen bei Frauen und Männern >übrig bleiben« « (Baltes-Löhr et al. 2005: 85).

Solche >resistenten Reste< zeigen sich in der aktuellen Untersuchung darin, dass Männer in einem signifikant geringeren Ausmaß von der gleichen Eignung von Frauen für Führungspositionen ausgehen, d.h., dass aus einer männlichen Perspektive betrachtet Männer immer noch eher für die Berufswelt und dort vor allem für die Entscheidungspositionen geeignet sind. Dieses Ergebnis strahlt sozusagen sowohl auf die Vorstellungen der Männer bzgl. existierender Diskriminierungen in der Berufswelt aus als auch auf männliche Haltungen in Bezug auf das eigene Privatleben. Männer meinen im Gegensatz zu Frauen eher, dass weibliche Kollegen heutzutage im beruflichen Feld nicht diskriminiert sind, und erklären sich selbst andererseits aber signifikant seltener dazu bereit, zur verbesserten Vereinbarkeit von Beruf und Familie die eigenen beruflichen Aktivitäten zu reduzieren. Dass diese Haltungen und Einstellungen immer noch gelebten Realitäten entsprechen, zeigt ein Blick auf die Zahlen, die angeben, wie hoch der Prozentsatz derjenigen Väter ist, die den Elternurlaub in Luxemburg in Anspruch nehmen. Lag der Anteil der Männer, die Elternurlaub nehmen, 2002 bei $13 \%$, stieg er bis zum Jahr 2006 auf $22 \%$ an. Ebenso wie auch schon in der Untersuchung »Die Bedeutung des Geschlechteraspektes für die berufliche und persönliche Entwicklung/Biographie von zukünftigen Erziehenden und Lehrenden « resümiert wurde, »dass Frauen kritischere Haltungen gegenüber Traditionalismen einnehmen « (Baltes-Löhr et al. 2005: 86), scheinen es auch im vorliegenden Fall die Frauen zu sein, die sich von traditionellen Vorstellungen hinsichtlich der Geschlechterrollen eher verabschiedet haben als die Männer. >Resistente Reste< aus sogenannten traditionellen Vorstellungen zeigen sich bei den Frauen vor allem hinsichtlich der Zuständigkeit für die Vereinbarkeit von Beruf und Familie und bei Männern in eher naturalistischen Vorstellungen von der essentiellen Unterschiedlichkeit der Geschlechter und der vorrangigen Eignung der Männer für die Berufswelt.

In den Interviewaussagen zeigt sich zu den Fragen der gesellschaftlich wahrgenommenen Geschlechterverhältnisse die gesamte Meinungspalette von: »Es ist gut so, wie es ist und es soll sich nicht ändern « über »Wir sind im Wandel und auf einem guten Weg« bis hin zu »Es geschieht zwar etwas, aber Gleichberechtigung oder Gleichstellung der Geschlechter bleiben unerreichbare Utopien«. Sowohl von Frauen als auch von Männern unterschiedlichen Alters wird betont, dass es Veränderungen auf dem Arbeitsmarkt gibt, dass immer mehr Frauen gute Bildungsabschlüsse haben, berufstätig sind und immer mehr Männer Erziehungsurlaub nehmen. 


\section{Kompetenz-, Leistungs- und Entlohnungsdiskurs}

Deutlich erkennbar ist ein >Kompetenzdiskurs<. Immer wieder wurde in den Interviews betont, dass es nicht so sehr auf das Geschlecht ankommt, wenn es um die Frage der Eignung für eine berufliche Tätigkeit geht, sondern um Kompetenzen und Qualität der erbrachten Leistungen. Kompetenz zählt, unabhängig von Geschlecht, Hautfarbe, Staatsangehörigkeit und Alter. Leistung zählt. In den Interviews wird Folgendes betont: Genau wie Männer sich aufgrund ihres Engagements und ihrer Leistung Respekt verschaffen, sollten Frauen das ebenso tun. Diesem Diskurs entspricht zweierlei: einmal die Vorstellung von der »defizitären Frau « (vgl. Baltes-Löhr 2006; 2009), die sich den männlichen Normen anpassen soll, wenn sie ebenso wie der Mann Anerkennung erlangen will, und zum Zweiten die Annahme von der Unattraktivität der Hausarbeit. Zu sagen, dass man Hausmann ist und zuhause staubsaugt, fänden nach Meinung zahlreicher Interviewpartnerinnen und Interviewpartner viele Männer uncool und dies sei für viele Männer der Grund, warum sie tatsächlich keine Hausarbeit machen. Als eindeutige Diskriminierung wird von den Interviewten immer wieder auf die Lohnungleichheit hingewiesen. Werden Kompetenzen, Qualität der Arbeit und Leistung eher als für beide Geschlechter geltende Grundlagen für gesellschaftliche Anerkennung und Positionierungen betrachtet, dann bleibt ungleiche Bezahlung ein Indiz für noch bestehende Diskriminierungen von Frauen. Häufig wird die ökonomische Unabhängigkeit von Frauen von den Interviews als Indiz für Emanzipation gedeutet.

Essentialistische Vorstellungen von Weiblichkeit und Männlichkeit finden sich in Aussagen zu den augenscheinlich wesenhaft anderen Arbeitsformen von Frauen und Männern. Ein drastisches Beispiel: Frauen könnten bestimmte Arbeiten körperlicher Anstrengung nicht so erledigen wie Männer, deshalb sei ungleiche Bezahlung gerechtfertigt. Wenn Frauen »so stark sind wie Männer«, dann würden sie dennoch weniger effektiv bleiben als ihre männlichen Kollegen. Diese essentialistisch anmutende Genderdifferenz wird mit den Hierarchisierungen der Arbeitswelt in Verbindung gebracht: Helfer, Maurer und Vorarbeiter auf der Baustelle würden ja auch unterschiedlich entlohnt.

\section{Andersheiten und resistente Reste}

Weitere >Andersheiten < werden in den Interviewaussagen deutlich: Sind bei Männern Selbstdarstellung, Betonung ihrer eigenen Wichtigkeit und Bedeutung dem tatsächlichen Tätigsein vorrangig, werden Frauen als themenzentrierter und gegenstandsbezogener erlebt und dargestellt. Frauen in Führungspositionen werden oft als spezifisch weiblich, also sanft, einfühlsam etc. und damit als >anders als männliche Chefs wahrgenommen oder es wird angenommen, sie müssten sich dem männlichen Stil anpassen. Letzteres verweist auf die Vorstellung, dass Geschlechterverhalten von Situationen abhängen kann, erlernbar und somit auch veränderbar ist. Die Annahme von der >spezifisch weiblichen Chefin< lässt jedoch auf eine tief verwurzelte essentialistische Vorstellung von Geschlecht schließen: 
Frauen bleiben auch in sogenannten männlichen Domänen stereotyp weiblich konnotiert. Stereotyp wesenhafte Weiblichkeit besteht in einem solchen Vorstellungsmuster auch hinsichtlich der Wahrnehmung in Bezug auf berufstätige Frauen ungebrochen weiter. Auch hier deuten sich wiederum >resistente Reste< an, wenn essentialistische Vorstellungen von Geschlecht nicht durch emanzipatorische Veränderungen wie die zunehmende Berufstätigkeit von Frauen gebrochen werden. Essentialistische Diskurse scheinen somit wirkmächtiger zu sein als faktische Veränderungen in Arbeitswelt und Politik. Um zu ergründen, wie genau diese Wirkmächtigkeiten konstruiert werden, wie also durch Wiederholungen Veränderungen, Verschiebungen sowie Konsistenzen und Ähnlichkeiten performativ hergestellt werden, bedarf es weiterer Forschungen.

Deutlich wird anhand der vorliegenden Daten, dass Frauen teilweise ebenfalls in ihren Residuen verharren. So betonen einige Befragte, dass Frauen ein gleichberechtigtes Miteinander der Geschlechter dadurch verhinderten, dass sie Männern beispielsweise nicht zutrauten, »Haushalt zu können«. Berufstätigkeit gilt zwar häufig, aber nicht in jedem Fall als Zeichen oder gar Symbol für Emanzipation. Frauen, die in traditionellen Rollen verbleiben wollen, möchten, so einige Interviewte, dennoch respektiert werden. Allerdings lässt sich festhalten, dass die Mehrzahl der Befragten davon ausgeht, dass mehr Frauen berufstätig seien als umgekehrt Männer in Haushalt, Erziehung und Pflege. So ist zu vermuten, dass die Durchlässigkeit zwischen den traditionellen >Geschlechterdomänen<, die Porosität der Geschlechtergrenzen ${ }^{5}$, von der sogenannten weiblichen in die sogenannte männliche Domäne ausgeprägter zu sein scheint als Grenzüberschreitungen von Männern in sogenannte weibliche Domänen wie Haushalt, Erziehung und Pflege.

\section{Umgang mit Anderssein und anderen}

\section{Die Bedeutung des Geschlechts im Umgang mit anderen Menschen}

Ausgehend von intersektional und pluridimensional verfassten Identitäten, die sich in ständigen Konstruktionsprozessen in Raum und Zeit verändern und als Ergebnisse permanenter Performanzen beschrieben werden können, wurde in der vorliegenden Untersuchung nach der Bedeutung der kulturellen Herkunft, der beruflichen Position, des Alters, des Geschlechts, der Religion sowie der sexuellen Orientierung für den Umgang mit anderen gefragt.

Es hat sich gezeigt, dass das Geschlecht an vorletzter Stelle rangiert, nur noch gefolgt von der Religion, die für den Umgang mit anderen noch unbedeutender zu sein scheint. Am wichtigsten sind das Alter und die kulturelle Herkunft, dann die berufliche Position und die sexuelle Orientierung. Das Geschlecht spielt vor

5 | Lässt das Bild der Porosität auf den ersten Blick eher eine gleichmäßige Fluidität und Durchlässigkeit von A nach B vermuten, dann wird dieses Bild hier insofern verschoben, als die jeweiligen Öffnungen der durchlässigen Poren als unterschiedlich groß bzw. ausgeprägt betrachtet werden. 
allem für Männer eine Rolle, wenn es um den Umgang mit anderen geht. Signifikant wichtig ist das Geschlecht im Umgang mit anderen auch für in Luxemburg lebende Italiener sowie für diejenigen, die einen Primärschulabschluss haben. Die sexuelle Orientierung ist vor allem bedeutsam für Männer, die Befragten portugiesischer Herkunft, für diejenigen, die einen Primärschulabschluss haben, für Arbeitslose sowie ebenfalls für Rentner. In Bezug auf das Alter, die Berufstätigkeit, den Familien- und Zivilstand zeigen sich keine signifikanten Werte im Antwortverhalten der Befragten. Die Bedeutsamkeit von Geschlecht (27\% Zustimmung) und sexueller Orientierung (34\% Zustimmung) spielt im unterprivilegierten Milieu die größte Rolle. Im alternativen Milieu wird dem Geschlecht die geringste Bedeutung beigemessen (9\%). Im statusorientierten Milieu ist die sexuelle Orientierung lediglich für $5 \%$ der Befragten für den Umgang mit anderen Menschen von Bedeutung.

\section{Homosexualität}

Eine Gleichwertigkeit von Homosexualität und Heterosexualität konstatieren $65 \%$ aller Befragten. Die signifikant höchsten Zustimmungen finden sich bei den Frauen (74 \%) im Gegensatz zu den Männern (57\%), den 21-29-Jährigen, Befragten mit deutscher Nationalität, Studierenden und >Gepacsten ${ }^{6}$. Im statusorientierten Milieu findet die Annahme der Gleichwertigkeit von Homo- und Heterosexualität die höchste Zustimmung (78 \%) und die geringste im konservativ-gehobenen Milieu (54\%).

In den Interviews geben einige der Befragten an, noch nie über diese Thematik nachgedacht zu haben. Ein Interviewpartner möchte sich nicht äußern, da er von sich selbst sagt, hierzu eine »rassistische« Einstellung zu haben, die er dann doch erläutert. Er meint, dass homosexuelle Menschen nicht normal wären und Homosexualität den Fortbestand der Menschheit bedrohe: »Wenn alle so wären, dann würde es keine Kinder mehr geben.« Hier zeigt sich, wie durch Homogenisierung: »Wenn alle so wären«, in Verbindung mit Generativität sozusagen der Minderheitenstatus von Homosexuellen konstruiert wird. Hierzu gehören auch Aussagen wie: Der homosexuelle Mensch spüre immer, dass er dem natürlich vorgegebenen Muster, dass Frauen und Männer füreinander gemacht seien, nicht entspricht. In der Mehrzahl der Interviews wird jedoch eher konstatiert, dass sich in Bezug auf den Umgang mit Homosexualität und mit Homosexuellen in Luxemburg etwas verändert habe und dass den >anderen $<$ mehr Toleranz entgegengebracht würde. Die zunehmende offizielle Akzeptanz entspräche jedoch nicht immer den inoffiziellen Meinungen und Haltungen. Daran habe auch die Ermöglichung einer eheähnlichen Gemeinschaft für gleichgeschlechtliche Paare (PACS) nichts grund-

6 | Mit dem Gesetz zu eingetragenen Partnerschaften wurden auch eheähnliche Gemeinschaften zwischen Gleichgeschlechtlichen ermöglicht. Gesetz vom 09.07.2004. Diejenigen, die eine solche Partnerschaft (Pacte civil de solidarité, abgekürzt PACS) haben eintragen lassen, werden im Folgenden mit dem Begriff ,Gepacste، bezeichnet. 
legend verändert: »Die Bevölkerung schaut aber immer noch schief.« Homosexuelle würden immer noch als andere, als anders und damit als komisch betrachtet. Der Begriff >schwul< tauge immer noch als Schimpfwort. Hierin spiegelt sich ein hegemonialer, heteronormativer Normalitätsdiskurs, wenn das Markierte als das >Nicht-Normale< gilt. (Knapp 2010: unveröffentlichter Redebeitrag anlässlich der Gründungstagung der Fachgesellschaft Geschlechterstudien in Berlin, 29./30.01.2010; Jakobson 1971) Häufig wird betont, dass das Kennen von homosexuellen Menschen hilft, bestehende Vorurteile abzubauen. Homosexualität wird von einigen Interviewten als Diskriminierung >von außen< verstanden. Es gehöre ein starkes Selbstbewusstsein dazu, sich zu outen: »Wenn der Homosexuelle die Homosexualität als Normalität betrachtet, dann kann er sich outen, wenn er sich nach der Familie oder den Freunden richtet, dann nicht.« Das Verständnis für die Angst vor einem Outing wird aber auch quantitativ begründet: »weil das [gemeint ist die Homosexualität] eine Ausnahme ist«. Hier wird die Angst vor dem Outing mit einem vermeintlichen Minderheitenstatus konnotiert, aber auch betont, dass Homosexuelle sich selbst nicht unbedingt als Minderheit betrachten. Quantitativität als Selbstverständlichkeit mehrheitlich orientiert verfasster Demokratien scheint oftmals mit einem eher schwach ausgeprägten Verständnis oder schwach ausgeprägter Toleranz bzgl. Minderheiten (Minderheitenschutz) einherzugehen: Die Mehrheit zählt und hat damit auch Recht. Die anderen bleiben letztendlich zur Anpassung aufgefordert oder marginal. Differenzkompetente Toleranz und Akzeptanz sowie die Sensibilität dafür, dass das Eigene sowie das kollektive Subjekt in der Mehrheitsposition für die marginalisierten anderen das Nicht-Eigene darstellen, fehlen häufig. Schwule Männer werden als einfühlsamere Menschen beschrieben, nicht nur im Vergleich zu anderen Männern, sondern auch - und das ist bemerkenswert - zu Frauen. Hier wird die traditionelle, essentialistische Geschlechterdualität überschritten, indem Einfühlsamkeit nicht sozusagen automatisch, als wesenhafte Verhaltensdisposition den Frauen per se zugeschrieben wird. Obwohl niemand der Interviewten sich selbst als schwul oder lesbisch bezeichnet, wird von einigen der Befragten Geschlechternormalität an sich explizit infrage gestellt; es werden Verunsicherungen zugegeben und es wird eingeräumt: »Wer weiß schon, was normal ist.«

Wie sehr liberale Einstellungen mit ethnisch konnotierten Diskriminierungen einhergehen können, zeigt die Aussage eines Interviewten, der meint, dass die Gesellschaft heute sehr viel liberaler mit dem Thema Homosexualität und mit Homosexuellen umgeht: »Heute ist alles liberaler, außer vielleicht bei den Portugiesen, die noch Angst haben, mit ihren Eltern darüber zu sprechen.« Auch hier zeigt sich, wie leicht oftmals selbst demokratisch motivierte Mehrheitsdiskurse Minderheiten konstruieren und diesen einen marginalisierten Status zuweisen, und wie nahe Toleranz und diskriminatorische Haltungen beieinander liegen können. 


\section{Transsexualität}

$75 \%$ aller Befragten können verstehen, dass es Menschen gibt, die sich in ihrer Geschlechterrolle nicht wohl fühlen und $52 \%$ haben Verständnis für Menschen, die ihr Geschlecht ändern wollen. Beim statusorientierten Milieu ist sowohl das Verständnis für Menschen, die sich in ihrer Geschlechterrolle nicht wohl fühlen, mit $80 \%$ sehr ausgeprägt als auch dasjenige für Transsexuelle mit $73 \%$. Am niedrigsten ist dieser Wert beim kleinbürgerlichen Milieu. Dort zeigen aber immer noch $70 \%$ Verständnis für das Unwohlsein mit der Geschlechterrolle. Deutlich geringer ist das Verständnis für Transsexuelle, das bei $43 \%$ rangiert.

Folgende Tabelle zeigt die signifikant höchsten bzw. niedrigsten Werte:

\begin{tabular}{|c|c|c|c|}
\hline Kategorien & $\begin{array}{c}\text { Höchste } \\
\text { Zustimmung }\end{array}$ & Item & $\begin{array}{c}\text { Niedrigste } \\
\text { Zustimmung }\end{array}$ \\
\hline $\begin{array}{l}\text { Geschlecht } \\
\text { Nationalität } \\
\text { Alter } \\
\text { Ausbildung } \\
\text { Berufstätigkeit } \\
\text { Arbeitsverhältnis } \\
\text { Familiensituation } \\
\text { Zivilstand }\end{array}$ & $\begin{array}{l}\text { Frauen } \\
\text { n.s. } \\
45-59 \\
\text { n.s. } \\
\text { n.s. } \\
\text { Hausfrau/-mann } \\
\text { n.s. } \\
\text { Gepacste }\end{array}$ & $\begin{array}{l}\text { Verständnis für } \\
\text { Unwohlsein mit } \\
\text { Geschlechterrolle }\end{array}$ & $\begin{array}{l}\text { Männer } \\
\text { n.s. } \\
60 \text { plus } \\
\text { n.s. } \\
\text { n.s. } \\
\text { Andere Beschäftigung } \\
\text { n.s. } \\
\text { Verwitwete }\end{array}$ \\
\hline $\begin{array}{l}\text { Geschlecht } \\
\text { Nationalität } \\
\text { Alter } \\
\text { Ausbildung } \\
\text { Berufstätigkeit } \\
\text { Arbeitsverhältnis } \\
\text { Familiensituation } \\
\text { Zivilstand }\end{array}$ & $\begin{array}{l}\text { Frauen } \\
\text { Deutsch } \\
\text { 30-59 } \\
\text { Universität } \\
\text { Hausfrau/-mann } \\
\text { Hausfrau/-mann } \\
\text { n.s. } \\
\text { Gepacste }\end{array}$ & $\begin{array}{l}\text { Verständnis für } \\
\text { Transsexuelle }\end{array}$ & $\begin{array}{l}\text { Männer } \\
\text { Portugiesisch } \\
60 \text { plus } \\
\text { Primär } \\
\text { Rentnerinnen/Rentner } \\
\text { Arbeitssuchende } \\
\text { n.s. } \\
\text { Verwitwete }\end{array}$ \\
\hline
\end{tabular}

Tabelle 1: Bewertungen von/Einstellungen zu Transsexualität (n.s.: nicht signifikant)

Deutlich wird zweierlei: Die Antworten zu dem Verständnis für das Unwohlsein mit der Geschlechterrolle zeigt in Bezug auf Nationalität, Ausbildung, Berufstätigkeit sowie Familiensituation keine signifikanten Werte, was darauf hindeutet, dass hier die Antworten über diese Kategorien hinweg gleich verteilt sind. Es sind die Frauen, die 45-49-Jährigen, im Haushalt Tätige und Gepacste, die hier mit deutlicher Signifikanz zustimmen.

Die Frage nach dem Verständnis für Transsexuelle polarisiert das Antwortverhalten stärker. Lediglich hinsichtlich der Familiensituation gibt es keine signifikanten Antworten. Auch hier sind es wieder die Frauen, die Altersgruppe der 30-59-Jährigen, Angehörige deutscher Nationalität, Akademikerinnen und Akademiker, zuhause Arbeitende sowie Gepacste, die in starkem Maße zustimmen. 
Geringste Zustimmung zu diesen Fragen, vor allem hinsichtlich der Einstellung zu Transsexuellen, gibt es bei Männern, der Altersgruppe der über 6o-Jährigen, Primarschulabsolventen, Verwitweten, bei Rentnerinnen und Rentnern sowie Arbeitssuchenden.

In den Interviews hat sich niemand als transsexuell bezeichnet. Lediglich drei der Interviewten geben an, Transsexuelle zu kennen. Einige erzählen, dass Bekannte Transsexuelle kennen, andere haben vage davon gehört und einige geben an, im Fernsehen Berichterstattungen darüber gesehen zu haben. Eine Befragte erinnert sich an eine Mitschülerin, die ausgesehen habe wie ein Junge, und meint, das könnte jemand sein, die später zum Jungen geworden wäre. Sie erzählt von der großen Verunsicherung, die damals vor ca. 15 Jahren im Gymnasium herrschte, wie mit dem Mädchen umzugehen sei. Generell wird Transsexualität in den Interviews in die Nähe der Homosexualität gerückt und/oder mit z.B. Brustvergrößerungen in Verbindung gebracht. Es wird oft erzählt, dass aus lauter Verunsicherung hinsichtlich des Umgangs mit transsexuellen Menschen diese häufig der Lächerlichkeit preisgegeben werden. Immer wieder wird die Wichtigkeit betont, bei ersten Anzeichen von transsexuellem Verhalten sofort Psychologen/-innen oder Ärzte/-innen hinzuzuziehen. Neben dieser Tendenz zur Pathologisierung wird auch Toleranz eingefordert und gleichzeitig unterstrichen, das sei in der Theorie einfacher als in der Praxis.

In den Interviews ist auch gefragt worden, wie die Interviewten mit einem Kind umgehen würden, das sich in seinem Geschlechtskörper nicht wohlfühlt. Die Antworten zeigen Unwissenheit, Hilflosigkeit sowie Unsicherheit im Umgang mit einem solchen Kind. Einige der Interviewten sagten, dass dies vielleicht/hoffentlich nur eine Phase sei: »Wenn es sich wieder einrenkt, ist es eben gut.« In Bezug auf Erwachsene hingegen sind andere Befragte der Meinung, es sei für diejenigen, die ihr Geschlecht verändern möchten, unbedingt notwendig, dies auch zu tun, da ein Verbleiben in einer solchen Unzufriedenheit auch krank machen könne.

Das Thema Transsexualität wird ebenso wie das der Homosexualität immer noch mit Angst in Verbindung gebracht und als Schicksalsschlag betrachtet. Je weiter das Thema in das eigene Privatleben hineinreicht, desto bedrohlicher scheint es zu werden. Es wird eine Demarkationslinie zwischen den Geschlechtern aufgebaut, wenn in den Interviews immer wieder betont wird, Männer hätten mit dieser Thematik mehr Probleme als Frauen. Aber es wird auch bemerkt, dass es möglicherweise für Mütter eine Herausforderung darstelle, wenn der Junge lieber ein Mädchen wäre oder umgekehrt. Letzteres wäre von der Mutter schwerer zu verstehen: schließlich sei sie selbst ja zufrieden damit, weiblich zu sein. Hier zeigt sich die Relevanz der Identifikation mit dem eigenen Geschlecht. Wird diese infrage gestellt, kommen Irritationen auf. So betont eine Interviewte, dass ein Vater mit dem Outing eines homosexuellen Sohnes größere Schwierigkeiten habe als eine Mutter, weil er ein Mann sei. 


\section{Gendermodelle}

\section{Favorisierte Gendermodelle: Egalitäre Rollenverteilung, solange kein Kind da ist}

Die Einstellungen zu den unterschiedlichen Gendermodellen wurden anhand folgender Fragen eruiert:

Welches Modell zur Arbeitsteilung in der Lebensgemeinschaft halten Sie für das beste?

A. Der Mann arbeitet Vollzeit, die Frau ist nicht erwerbstätig und sie kümmert sich um Haushalt und Familie

B. Der Mann arbeitet Vollzeit, die Frau in Teilzeit und kümmert sich um Haushalt und Familie

C. Beide Partner teilen sich gleichberechtigt Erwerbsarbeit, Haushalt und Familie

D. Die Frau arbeitet Vollzeit, der Mann in Teilzeit und kümmert sich um Haushalt und Familie

E. Die Frau arbeitet Vollzeit, der Mann ist nicht erwerbstätig und kümmert sich um Haushalt und Familie

Die einzelnen Modelle erhielten folgende Zustimmungen:

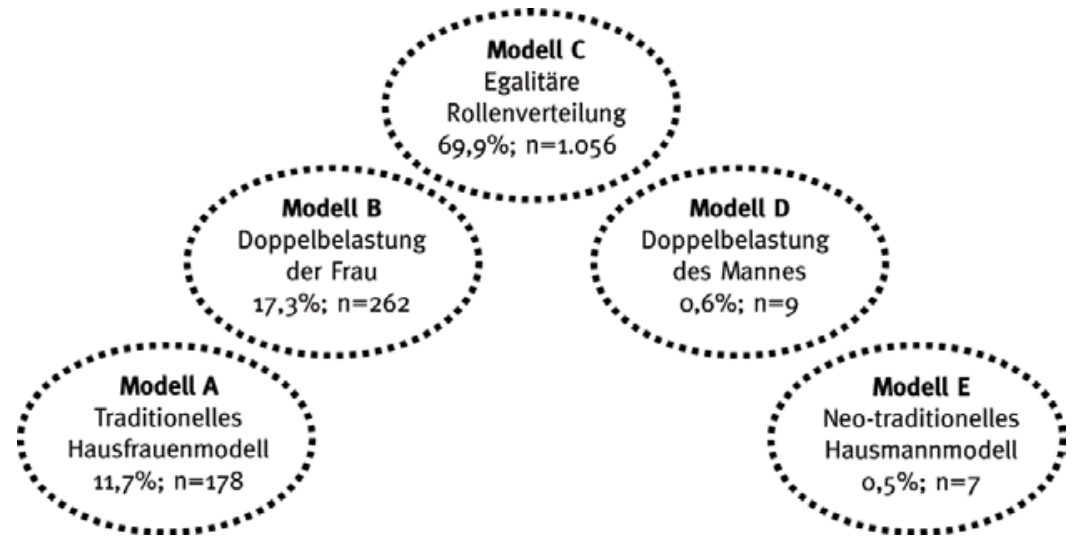

Abbildung 1: Zustimmung zu den Modellen A-E in \% und absoluten Zahlen der Zustimmenden

Da die Berechnung der Signifikanzen für die Modelle D und E aufgrund der geringen Antworten nicht möglich ist $(\mathrm{n}<30)$, soll im Folgenden kurz beschrieben werden, welche Personengruppen hier am häufigsten geantwortet haben: Modell D wird vor allem befürwortet von jungen, alleinstehenden oder in Partnerschaften mit oder ohne Kinder lebenden Studierenden, die in 3-5-Personenhaushalten, wohlmöglich in stadtnahen WGs oder in der elterlichen Wohnung, leben und französischer Herkunft sind. Diejenigen, die diesem Modell zustimmen, kommen aus allen Einkommensklassen außer derjenigen zwischen 5000 und $7000 €$ und sind im alternativen Milieu am stärksten vertreten. Das Modell E findet erstaunlicher- 
weise vor allem Zustimmung bei den über 45-Jährigen, bei Menschen, die ohne Kinder leben, Menschen, die verwitwet sind, in 1- oder 2-Personenhaushalten in Mietwohnungen oder als Eigentümer wohnen. Menschen mit einem Haushaltseinkommen von 4000-5000 € stimmen am ehesten diesem Modell zu, ebenso wie Zugehörige zu dem hedonistischen Milieu.

Überaus erstaunlich ist die Häufigkeit der Nennung von Modell C, wird doch hier die egalitäre Aufgabenverteilung zwischen den Geschlechtern eindeutig favorisiert. In Bezug auf die Modelle A, B und C unterscheidet sich das Antwortverhalten der Frauen und Männer nicht signifikant. Unterschiedliche Geschlechtermodelle repräsentieren sich also mit deutlicher Trennschärfe, ohne dass das Geschlecht des Befragten hier als diskriminierende Kategorie nachzuweisen ist. Dies deutet darauf hin, dass die Vorstellungen zu unterschiedlichen Geschlechtermodellen nicht über die Geschlechterzugehörigkeit selbst (re-)produziert werden, sondern dass möglicherweise andere Kategorisierungen hinsichtlich der Geschlechtermodelle wirkmächtiger sind. Das heißt u.a., dass Ansätze zu intersektionalen Betrachtungen angemessen zu sein scheinen, wenn es um die Erklärung bestehender Repräsentationen zu Geschlechterfragen geht.

Kinderlosigkeit scheint die Zustimmung zu dem egalitären Modell zu erhöhen, sowohl bei denjenigen, die in einer Partnerschaft als auch alleinstehend leben. Anders ausgedrückt: Sobald Kinder in Beziehungen eintreten, nimmt die Zustimmung zu egalitären Partnerschafts- und Berufsmodellen ab. Gleichberechtigung lässt sich dann am ehesten befürworten, wenn sie nicht mit der lebensweltlichen Realität der Kindererziehung konfrontiert wird. Elternschaft/Kinderlosigkeit spielen somit im Kontext der Zuschreibungs- und Aneignungsprozesse von Identitäten eine nicht $\mathrm{zu}$ vernachlässigende Rolle und sollten im intersektionalen Kanon Berücksichtigung finden.

Zeigen sich bei den Modellen A und C deutliche Unterschiede im Antwortverhalten, dann ist bei Modell B die prozentuale Spannbreite im Antwortverhalten gering. Hieraus ließe sich schließen, dass dieses Modell der Doppelbelastung der Frau über alle Kategorien wie Alter, Schulbildung etc. hinweg am ehesten von einer breiten Bevölkerungsgruppe akzeptiert wird.

Findet das Modell C zwar mit der egalitären Aufgabenverteilung die höchste Zustimmung, so geben allerdings lediglich $51 \%$ aller Befragten an, dass sie selbst bereit wären, beruflich kürzer zu treten, um z.B. Familie und Beruf besser miteinander vereinbaren zu können. Auch wenn die Zustimmung zu Modell C keine Geschlechtersignifikanz im Antwortverhalten erkennen lässt, dann sind jedoch immer noch signifikant mehr Frauen bereit, zur Verbesserung der Vereinbarkeit von Beruf und Familie ihre eigenen beruflichen Ambitionen zurückzustecken.

Folgende Tabelle gibt Aufschluss über höchste und geringste Zustimmungen zu den Modellen A, B und C: 


\begin{tabular}{|c|c|c|}
\hline Höchste Zustimmung & Modelle & Geringste Zustimmung \\
\hline $\begin{array}{l}\text { Über 6o-Jährige } \\
\text { Luxemburgische Nationalität } \\
\text { Partnerschaft mit Kindern } \\
\text { Verwitwete } \\
\text { mithelfende Familienangehörige } \\
\text { Primarschulabschluß }\end{array}$ & $\begin{array}{c}\text { Modell A: } \\
\text { Traditionelles } \\
\text { Hausfrauenmodell }\end{array}$ & $\begin{array}{l}\text { 20-29-Jährige } \\
\text { Französische Nationalität } \\
\text { Alleinstehend ohne Kinder } \\
\text { Getrennt, ledig, gepacst } \\
\text { Studierende, Selbständige, } \\
\text { Beamtinnen und Beamte } \\
\text { Etudes Supérieures }\end{array}$ \\
\hline $\begin{array}{l}\text { Alle Altersgruppen außer 20-29-Jährige } \\
\text { Italienische Nationalität } \\
\text { Partnerschaft mit Kindern } \\
\text { Gepacste } \\
\text { Angestellte } \\
\text { Andere Bildungsabschlüsse }\end{array}$ & $\begin{array}{c}\text { Modell B : } \\
\text { Doppelbelastung } \\
\text { der Frau }\end{array}$ & $\begin{array}{l}\text { 20-29-Jährigen } \\
\text { Britische Nationalität } \\
\text { Alleinstehend ohne Kinder } \\
\text { Ledige } \\
\text { Studierende } \\
\text { Universität }\end{array}$ \\
\hline $\begin{array}{l}\text { 20-29-Jährige } \\
\text { Britische Nationalität } \\
\text { Alleinstehende ohne Kinder } \\
\text { Ledige } \\
\text { Studierende } \\
\text { Universität }\end{array}$ & $\begin{array}{c}\text { Modell C: } \\
\text { Egalitäre } \\
\text { Rollenverteilung }\end{array}$ & $\begin{array}{l}\text { Über 60-Jährige } \\
\text { Italienische Nationalität } \\
\text { Partnerschaft mit Kindern } \\
\text { Verwitwete } \\
\text { Mithelfende } \\
\text { Familienangehörige } \\
\text { Primarschulabschluß }\end{array}$ \\
\hline
\end{tabular}

Tabelle 2: Präferenzen der Gendermodelle

Das Modell A, traditionelles Hausfrauenmodell, wird am ehesten im kleinbürgerlichen Milieus favorisiert; Modell B, Doppelbelastung der Frau, wird mit jeweils $20 \%$ gleich von Zugehörigen mehrerer Milieus präferiert: denjenigen des kleinbürgerlichen, des unterprivilegierten, des statusorientierten und des aufstiegsorientierten Milieus. Modell C, egalitäre Rollenverteilung, wird vor allem im liberal-gehobenen Milieu favorisiert. Modell D, Doppelbelastung des Mannes, findet, wie schon weiter oben erwähnt, höchste Zustimmung im alternativen Milieu und Modell E, das neo-traditionelle Hausmannmodell, im hedonistischen Milieu.

\section{Gelebte Gendermodelle}

Aus den Interviews geht deutlich hervor, dass alle Gendermodelle vorkommen. Immer wieder wird betont, dass Frauen und Männer die Möglichkeit zur freien Entscheidung haben sollten, wie sie sich in ihrem Privatleben arrangieren. Allerdings wird auch erzählt, dass fehlende Kinderbetreuungseinrichtungen, mangelnde Qualität dieser Einrichtungen und finanzielle Zwänge die Entscheidungen, wer zuhause bleibt, beeinflussen. Viele weibliche Befragte berichten, dass sie gerne als Mutter zuhause bleiben; vereinzelt wird aber auch genau nachgezeichnet, wie sehr dann doch der Außenkontakt und eine intellektuelle Betätigung vermisst werden. Thematisiert wird auch die >Mütterkonkurrenz<, z.B. das Organisieren von 
Kindergeburtstagsfeiern als Messlatte für die >Qualität< der Mütter. Es wird immer wieder betont, dass Kindererziehung >vollen Einsatz< erfordere, dass Männer sich oft nicht dazu in der Lage sähen, den erzieherischen oder haushälterischen Anforderungen gerecht zu werden. Sie würden sich erzieherische Tätigkeiten vor allem bei Babys oder Kleinkindern - selbst wenn es ihre eigenen Kindern sind nicht zutrauen. Auch wird deutlich, dass gemeinschaftlich organisierte Haushalte sich verändern, wenn ein Kind geboren wird: Die Frauen bleiben i.d.R. zuhause. Kindererziehung ist für Männer immer noch keine Selbstverständlichkeit. Dies bestätigt die Ergebnisse, die weiter oben in dem Abschnitt »Favorisierte Gendermodelle« vorgestellt wurden, dass die partnerschaftliche Rollenverteilung eng mit Kinderlosigkeit bzw. Elternschaft verknüpft ist. Wenn Männer jedoch in Haushalt oder Kindererziehung der etwas älteren Kinder (meistens ab vier Jahren) aktiv werden, dann erzählen sowohl sie selbst als auch ihre Partnerinnen, dass dies oft mit Spaß und Freude verbunden sei.

Ein anderer Faktor, der zu einer nicht-traditionellen Verteilung von Hausarbeit und Kinderbetreuung beitragen, ist berufliche Selbstständigkeit, die eine Vereinbarkeit von Beruf und Familie erleichtert, weil hier flexible Arbeitszeiten auch Vätern ermöglichen, sich mehr um die Kinder kümmern zu können. Auch wird der Aspekt der Effektivität genannt: Wer kann was am besten und am schnellsten? Daneben rangieren Körpergröße, berufliche Belastung und der Zeitfaktor. Beim Kochen hängt auch viel davon ab, was gekocht werden soll und für wen das Essen ist, also der Geselligkeitsgrad. In einem Fall kocht die Frau bei englischsprachigem Besuch, damit sie sich nicht auf Englisch unterhalten muss, das macht dann der Mann. Hier begegnen sich Geschlecht, Kultur, Herkunft und Sprachkompetenz und Kochen: ein deutliches Beispiel dafür, wie Intersektionalität sich in der Alltagspraxis abbildet. Aber auch die goffmansche Vorder- und Hinterbühne (Goffman 1969) tauchen in den Interviews auf, wenn erzählt wird, dass in einem als partnerschaftlich deklarierten Verhältnis die Frau für die Wascharbeit im Keller zuständig ist und er für das, was sich >oben< abspielt: Sie wäscht und hängt auf; er bügelt und faltet. Dieses Bild wiederholt sich interessanterweise bei der räumlichen Aufteilung des Putzens: »Sie putzt den hinteren Teil der Wohnung und ich den vorderen.«

In Bezug auf die Frage, woher die Entscheidung für ein verändertes Gendermodell kommt, zitieren einige Interviewte ihre Eltern als Vorbild. Andere betonen, dass sie bewusst im krassen Gegensatz zu dem, was sie im Elternhaus erlebt haben, ihr eigenes Gendermodell entworfen und realisiert haben. Um diese Wege der Veränderungen jedoch genauer zu ergründen, besteht erheblicher Forschungsbedarf.

Traditionelle Gendermodelle werden oftmals als vollkommen normal und selbstverständlich dargestellt. Das Traditionelle wird nicht hinterfragt. Auch wird oft betont, dass man darüber noch nicht einmal zu reden brauche. Deutlich werden hier die Unausgesprochenheit von Normalitätsdiskursen und die damit verbundene >diskussionsfreieく Übernahme von Rollenzuschreibungen. Dies könnte 
als Beleg für die Annahme gelten, dass im hegemonialen Normalitätsdiskurs nur das Nicht-Normale markiert wird. So zeigt sich in den Interviews, dass das >noch Normale oftmals von denjenigen, die sich davon gelöst haben, belächelt zu werden scheint. Was wiederum bei den >Traditionalisten < zum Ärger über die sogenannte Arroganz der >anderen < führen kann.

\section{Kenntnisse in Bezug auf Maßnahmen und Gesetze zur Gleichstellung von Frauen und Männern}

Vor allem die über 6o-Jährigen kennen Gesetze oder luxemburgische Regelungen zur Gleichstellung von Frauen und Männern. Der »Girls' und Boys’ Day« (GBD), den es für Mädchen seit 2002 und auch für Jungen seit 2005 in Luxemburg gibt, und mit dem Mädchen und Jungen für sogenannte atypische Berufe sensibilisiert werden sollen, ist hingegen eindeutig eher bei den 16-20-Jährigen bekannt. Ist der Girl's Day bei Frauen und Männern gleichermaßen bekannt, dann zeigt sich eindeutig, dass Männer eher die Gesetzesregelungen kennen und Frauen eher auch vom Boy's Day gehört haben. Die Gesetze und Regelungen sind am ehesten den in Luxemburg lebenden Deutschen bekannt; der GBD ist eindeutig der luxemburgischen Bevölkerung am ehesten bekannt. Insgesamt nimmt das Kennen von Gesetzen, Regelungen und dem GBD relativ zur Höhe des Bildungsabschlusses zu.

Aus den Interviews geht eine bemerkenswerte Unkenntnis hinsichtlich bestehender Gesetze und Regelungen hervor. Mehr oder weniger bekannt sind: Schwangerschaftsschutzregelungen, Wegweisungsgesetz, Gesetze zur gleichen Bezahlung, Personenstandsgesetze, Scheidungsgesetzgebung, eingetragene Partnerschaften. Bei aller Unwissenheit wird dennoch mehrfach mit Nachdruck behauptet, dass Gesetze die Tendenz hätten, Frauen zu favorisieren. Proportional zur Unkenntnis wird die Bedeutung der Gesetze und Regelungen für den Alltag negiert. Die Tatsache, in einer Vertragsgesellschaft zu leben, scheint den Befragten kaum bewusst zu sein. Gesetze und Regelungen scheinen nur für besondere Fälle notwendig zu sein, wie z.B. bei Gewalt in der Ehe. Auch wird betont, dass man selbst für seine Rechte kämpfen müsse, auch wenn es um Gleichberechtigung geht. Die Quotendebatte wird häufig als Nonsens abgetan. Hier zeigt sich eine interessante Querverbindung zum Kompetenzdiskurs, wenn gesagt wird, es komme auf die Kompetenz an und nicht auf das Geschlecht. Geschlechterdisparitäten seien nicht durch Regelungen abzubauen. Dies sei eine Frage der Bildung, der Erziehung und der Änderung der inneren Haltung, und das brauche Zeit.

\section{Geschlechterkategorie im polyfonen Chor der Intersektionalität}

Wurde Gender bis in die späten 1990 er Jahre im wissenschaftlichen feministischen Diskurs als die Strukturkategorie betrachtet, dann zeigen die vorliegenden Ergebnisse, dass Geschlecht als Analysekategorie an Trennschärfe verloren hat. Gender wird zu einem Aspekt im polyfonen Chor der Intersektionalität und somit ent- 
dramatisiert. Je nach Situation scheinen einzelne Sektionen im Identitätsgeflecht mehr oder weniger stark auf. Mal ist das Alter, mal die berufliche Positionierung, mal die sexuelle Orientierung bedeutsamer und wird zum das Subjekt kenntlich machenden Aspekt. So nimmt Geschlecht im Umgang mit anderen Menschen nach den vorliegenden Ergebnissen eine eher nachgeordnete Rolle ein. Geht es um Annahmen zu Weiblichkeiten und Männlichkeiten, dann zeigen sich essentialistische und konstruktivistische Vorstellungen zu Identitäten und Geschlechtern als diskursiv eng verwoben. Hier deutet sich möglicherweise eine erstaunliche Nähe und Überschneidung dieser paradigmatisch oftmals dichotom verorteten Diskursfiguren an. Ähnliches gilt für Toleranz und diskriminatorische Haltungen. Hegemoniale Normalitätsdiskurse scheinen in Bezug auf die Präferenzen von Geschlechtermodellen ebenso brüchig geworden zu sein wie tradierte Vorstellungen über Homo- und Transsexualitäten, obwohl sie ihre Wirksamkeit als Instrument des Ein- und Ausschlusses noch nicht eingebüßt haben und immer noch zu Marginalisierungen von Minoritäten beitragen können. Dennoch hat sich - so die Ergebnisse - in der luxemburgischen Gesellschaft viel getan hinsichtlich einer zunehmenden Geschlechtergerechtigkeit, die Geschlechtergrenzen sind poröser geworden, wobei die Durchlässigkeit noch nicht ausbalanciert zu sein scheint: Es ist wohl einfacher, von der sogenannten weiblichen Seite auf die sogenannte männliche zu gelangen, als umgekehrt. Dennoch zeigt sich deutlich, dass traditionelle Geschlechterbilder ihre Wirkmächtigkeit keineswegs vollständig verloren haben, vor allem wenn es um Elternschaft geht. Elternschaft scheint immer noch die Umsetzung egalitärer Partnerschafts- und Berufspraxen zu erschweren. Frauen sind immer noch eher als Männer zu einer Priorisierung der Familie zuungunsten ihrer eigenen beruflichen Tätigkeit bereit. Faktische Strukturveränderungen wie zunehmende Erwerbstätigkeit von Frauen, zunehmend bessere Bildungsabschlüsse sowie zunehmende Präsenz von Frauen in Politik und Öffentlichkeit (Allegrezza et al. 2007; Ministère de l'Egalité des Chances 2006; Ministère de l'Education nationale et de la Formation professionnelle 2007) haben nachgewiesenermaßen keinen unbedingten Einfluss auf die Einstellungen der Menschen hinsichtlich der Geschlechterthematik. Es kann somit von >resistenten Resten den, die sich bei Frauen eher im Bereich der Mütterlichkeit und der Zuständigkeit für die Vereinbarkeit von Beruf und Familie zeigen und bei Männern in naturalistisch begründeten Annahmen essentiell unterschiedlicher Geschlechter sowie der vorrangigen Eignung der Männer für die Berufswelt.

Solche geschlechterpolarisierende Zuschreibungsprozesse können jedoch durchaus geschlechterübergreifend von allen Geschlechtern gemacht werden. Trotz dieser >resistenten Reste< scheinen (Geschlechts-)Identitäten immer mehr als permanente Performanzen im intersektionalen Kanon auf. Sie konstruieren einen Raum, in dem sich Subjekte interaktiv verorten, in dem auch immer wieder die Geschlechtszugehörigkeiten der Agierenden eine Rolle spielen - können. Die Wirkmächtigkeit der Kategorien ist in Bewegung. Die Kategorie Geschlecht ist in Bewegung geraten: gender in motion. 


\subsection{IGUtes، EsSEN. OSZILLATION ZWISCHEN POLITISCHEM LeItBiLd UND INDIVIDUElLer AlltagspraXis}

\section{Identitätsrelevante Essensnormen und -praxen erforschen}

Im folgenden Fallbeispiel für Identitätskonstruktionen geht es um normative Vorstellungen darüber, was unter >gutem « Essen zu verstehen sei bzw. wie dieses sozial praktiziert wird. Der sowohl qualitativ wie quantitativ ausgerichtete Analysekorpus erfasst zugleich die institutionelle und die individuelle Dynamik: Er basiert einerseits auf einem Gruppeninterview mit Experten/-innen sowie auf politischen Veröffentlichungen zum Thema und andererseits auf einer Repräsentativumfrage sowie qualitativen Interviews in der Luxemburger Wohngesellschaft.

Diese Forschungsthematik bietet die Möglichkeit, durch das banale und wiederkehrende Ernährungsbedürfnis der Subjekte das Ineinandergreifen von normativen Einflüssen mit weitgehend routinisierten und unhinterfragten Diskurspraktiken zu untersuchen. Diese werfen aufgrund des menschlichen Omnivorismus ${ }^{7}$ (Fischler 1990) Fragen über die ressourcenabhängige Nahrungsauswahl (was essen?), über deren Zubereitung und Zusammenstellung (wie essen?) sowie über den gemeinsamen Verzehr mit ausgewählten Mitmenschen (mit wem essen?) auf. Die allägliche, individuelle Bewältigung dieser Fragen (>Perceptas $<$ ) ermöglicht einen analytischen Blick auf die ihr zugrunde liegenden und kollektiv verfügbaren Werte, Einstellungen und Normen (>Conceptas $<)^{8}$ - was wiederum einen Rückschluss auf sinnstiftende und über Alltagshandeln artikulierte Prozesse der Identitätsarbeit ermöglicht. (Vgl. Keupp et al. 2006) Dabei wird der Begriff der Identitätsarbeit hier sowohl als Form der individuellen Selbstkonstruktion als auch der kollektiven Mitgestaltung auf gemeinschaftlicher bzw. gesellschaftlicher Ebene aufgefasst. Denn gerade durch körpergebundene Handlungen wie beim Essen konstruiert sich das Individuum bewusst als >Ich < mit idiosynkratischen Präferenzen und Gewohnheiten. Gleichzeitig wird es von den inkorporierten Speisen physiologisch wie auch symbolisch konstituiert. Es gestaltet kollektive Normen von >gutem< Essen, indem es sie zwar individuell interpretiert, jedoch ohne den tradierenden Rahmen zu sprengen. Gleichzeitig wird das individuelle Handlungsrepertoire - zu dem Rezepte, Menüzusammenstellungen, Geschmacksvorlieben, Tischmanieren, Mahlzeitengestaltung, Werte und Einstellungen in Bezug auf Essen oder Essensgespräche etc. zählen - von kursierenden, kollektiven (kulturellen, sozioökonomischen und milieuspezifischen) Einstellungen, Denk- und Wissensbeständen gerahmt. (Bourdieu 2000; 1994; 1980) Alltägliches Essverhalten und individuelle bzw. kollektive Identitäten sind demnach eng miteinander verwoben; dennoch ist ihre Beziehung weder eindeutig noch gleichbleibend. (Scholliers et al. 2001)

7 | Die physiologische Tatsache, dass die Menschen nahezu alles essen können - jedoch in einem Rahmen des kulturell Akzeptablen.

8 | Vgl. Abschnitt 7.1. 
Besonders den selbstverständlich erscheinenden Aspekten identitätsrelevanter Diskurspraktiken haftet eine gewisse Unsichtbarkeit, Unsagbarkeit und Intimität an. Dies zieht forschungspraktische Konsequenzen nach sich, da Interviewte in einem qualitativen semidirektiven Gespräch - aufgrund des für viele ungewöhnlichen Themenfelds und der oft wenig ausgeprägten Selbstreflexivität in Bezug auf die eigene Essenspraxis - nicht ohne weiteres die uns interessierenden Sinnzusammenhänge und Wertvorstellungen verbalisieren. Eine Konsequenz für die Interviewführung bestand darin, das Gespräch auf das Thema der kollektiven Identifikationen zu lenken. So haben die Interviewten die Themenfelder Essen und Identität über ethnische, nationale oder familiäre Zugehörigkeit durch ostentatives oder festliches, oftmals stereotypisiertes Verzehren von bestimmten Gerichten oder Zutaten zu bestimmten Gelegenheiten artikuliert. ${ }^{9}$ So hieß es z.B.: »Wir Portugiesen essen viel Fisch « oder: »Quand on va boire un café dans un bistrot en Italie, dans n'importe quelle ville, on papote avec tout le monde sans problème«. Solche Verbalisierungen auf kollektiver Ebene erscheinen unproblematisch, geht es dabei doch lediglich um das Anknüpfen an bestehende kollektive Zuschreibungen, deren Konstruktionen bereits abgeschlossen sind und als kulturelle Identitätsangebote zur Verfügung stehen. Hingegen scheint es für die Interviewten ungleich komplexer, Essen und Identität auf individueller Ebene zu verbalisieren. Dies ist der Bereich der als problematisch empfundenen Selbstkonstruktion, d.h. der impliziten, nie abgeschlossenen Subjektivierung. Diese ist von Wahlmöglichkeiten zwischen unterschiedlichen normativen Angeboten geprägt (Corbeau/Poulain 2002) ${ }^{10}$ und erzeugt dementsprechend Unsicherheit aufgrund unzureichender Eindeutigkeit. Letztgenannte kann als Infragestellung des Selbst und damit als ein allgemeines Gefühl der Angreifbarkeit im Zuge der eigenverantwortlichen Modellierung von >Identity in Progress< empfunden werden.

Um die beschriebenen Problembereiche aufzufangen, wurde das Forschungsinteresse auf ein externes und kontrastives Moment gerichtet. Dieses bestand in der von den Befragten vollzogenen Positionierung der eigenen ernährungsbezogenen Diskurspraktiken hinsichtlich eines spezifischen Konzepts von >gutem< Essen. Dabei handelte es sich um den von vier luxemburgischen Ministerien koordinier-

9 | Es war nicht Ziel dieser Untersuchung, die Rolle von ,Produits du Terroir und regionaler Küche in luxemburgischen Identitätskonstruktionen zu analysieren; dies wird an anderer Stelle erfolgen.

10 | Die Vielfalt der möglichen Speiseplangestaltungen soll, den Nahrungsmittelherstellern und -vertreibern nach, die privaten Entscheidungen vereinfachen, indem sie repetitive Langeweile vermeidet; tatsächlich stiften die unterschiedlichen normativen Orientierungen hinter den vielfältigen Produkten jedoch Verwirrung. So koexistieren etwa industrielle, aus Massenzüchtung gewonnene Fertiggerichte mit biologischen Konserven ohne Genmanipulation. Beide vereinfachen die Essenszubereitung, entsprechen aber diametral entgegengesetzten Produktionsketten und Konsumpositionierungen. 
ten ${ }^{11}$ und im Juli 2007 verabschiedeten nationalen Aktionsplan mit dem programmatischen Titel »Gesond iessen, méi bewegen«. Dieser nationale Aktionsplan (im Folgenden GIMB) wird hier als die institutionelle Zuschreibung eines Identifikationsangebotes aufgefasst, das als politisch und gesellschaftlich wünschenswert dargestellt wird. Dieser Eindruck wird umso deutlicher, wenn die Grundlagen des Aktionsplans - internationale Vergleiche wissenschaftlicher Befunde sowie moralisches Regierungsbestreben im Bereich der >Public Health< (s.u.) - berücksichtigt werden. Die konvergierenden ebenso wie die divergierenden Wechselwirkungen zwischen diesen moralisch gelagerten, kollektiven Zuschreibungen einerseits und der ethisch ausgeprägten, individuellen Aneignungen andererseits ${ }^{12}$ geben Aufschluss über die dynamische Identitätsarbeit der Subjekte im luxemburgischen Kontext.

\section{Gesundheitsorientierung auf politischer Ebene}

\section{Politisches Handlungskonzept}

Zur Annäherung an die Frage, welche performative Zuschreibung im Sinne eines moralischen Identifikationsideals über GIMB vermittelt wird, gilt es zunächst das Selbstverständnis der politisch Verantwortlichen zu erläutern. Die Ausgangsannahmen für die politische (prophylaktische und ggf. korrektive) Intervention hinsichtlich >Public Health< in den Bereichen der Ernährung und Bewegung basieren auf vergleichenden wissenschaftlichen Studien der Weltgesundheitsorganisation (u.a. WHO 1999; WHO 2008) und der Europäischen Kommission (u.a. CE, 2007; CE 2005). Insbesondere auf der Definition von Fettleibigkeit (Adipositas) als Epidemie, welche mit steigender Kaufkraft einhergehe und eine Serie von Sekundarerkrankungen ${ }^{13}$ mit sich ziehe, wird rekurrierend Bezug genommen. Auf nationaler Ebene zeigte eine vom luxemburgischen Gesundheits- und Bildungsministerium

11 Im Einzelnen handelt es sich um die zuständigen Ministerien in den Bereichen Gesundheit, Erziehung, Familie und Sport.

12 | Wir folgen Foucault in seiner Unterscheidung zwischen Moral und Ethik. Die Moral steht für "ein Ensemble von Werten und Handlungsregeln, die den Individuen und Gruppen mittels diverser Vorschreibapparate - Familie, Erziehungsinstitutionen, Kirchen usw. - vorgesetzt werden. Es kommt vor, daß diese Regeln und Werte sehr ausdrücklich in einer zusammenhängenden Lehre und in einem ausführlichen Unterricht formuliert werden. Es kann aber auch sein, daß sie in diffuser Weise übermittelt werden und daß sie kein systematisches Ganzes, sondern ein komplexes Spiel von Elementen bilden, die sich kompensieren, korrigieren, stellenweise aufheben und dergestalt Kompromisse oder Ausflüchte gestatten." (Foucault 1984a: 36) Dieser "moralische Code" geht Hand in Hand mit der "Art und Weise, wie man sich führen und halten - wie man sich selber konstituieren soll als Moralsubjekt, das in Bezug auf die den Code konstituierenden Vorschriften handelt" (Ders.: 37).

13 | Herz-Kreislauf-Erkrankungen, Krebs, Typ-2-Diabetes, Osteoporose etc. 
durchgeführte Studie ${ }^{14}$ ähnliche Ergebnisse wie in den Nachbarländern, was ähnliche Handlungsstrategien der politischen Entscheidungsträger im Rahmen von GIMB legitimierte - von der Einbindung in europäische und internationale Netzwerke bis hin zum Austausch über die jeweiligen Strategien.

Vor diesem Hintergrund sind etwaige Besonderheiten des Großherzogtums nicht in der Ausgangsproblematik angesiedelt, sondern in der Umsetzung der politischen Intervention ${ }^{15}$. Das institutionelle Vorgehen auf nationaler Ebene basiert auf einem Experten/-innen-Ausschuss ${ }^{16}$, einem interministeriellen Ausschuss ${ }^{17}$ und auf öffentlichen Texten ${ }^{18}$. Konzeptionell folgt das Vorgehen den Prinzipien von >Health in All Policies ${ }^{19}$, der Politik der Santé ${ }^{20}$ und der European Charter on Counteracting Obesity ${ }^{21}$. Ausgehend von einem »multifaktoriellen ${ }^{22}{ }^{2}$ Verständnis von Gesundheit, ziehen diese Ansätze einen interdisziplinären und intersektiona-

14 | Ministère de l'Education Nationale et de la Formation Professionnelle/Ministère de la Santé/Universität Karlsruhe 2006.

15 | Zunächst bedeutet die gängige zwei- bis viersprachige Kommunikation (Deutsch und Französisch, ggf. erweitert auf Portugiesisch und Englisch) einen erheblichen Mehraufwand, aber gleichzeitig durch die Berücksichtigung unterschiedlicher kultureller Muster und Referenzen einen Mehrwert.

16 | Hier diskutierten vor allem Mediziner/-innen unterschiedlicher Fachbereiche über einen wissenschaftlich-technischen Konsens über national definierte Ernährungsrichtlinien. Insbesondere ging es um eine nachhaltige und aktive Implizierung in die Gestaltung einer ,Public-Health-Politik, d.h. darum, "Partner zu vereinen und sie zu begeistern".

17 | Dieser hat eine Koordinierungs- und Evaluierungsrolle der von Partnerinstitutionen eingereichten Projekte, welche unter dem Label und dem Logo GIMB laufen sollen.

18 | Insbesondere die am 05.07.2006 von vier Ministerien (Gesundheit, Erziehung, Sport, Familie) unterzeichnete "Politique commune favorisant l'alimentation saine et l'activité physique", in Form des "Programme national pour la promotion de l'alimentation saine et de l'activité physique 'Gesond iessen méi bewegen'", aber auch die Kriterien, die eingereichte Projekte aufweisen müssen, um das Benutzungsrecht des Labels und des Logos GIMB zu erhalten.

19 | Leitinitiative des finnischen Ministeriums für Soziales und Gesundheit (in internationaler politischer Kooperation) während der finnischen EU-Präsidentschaft im Jahr 2006, zur Förderung von "gesunden Entscheidungen" und "Gesundheitsbildung" (Ståhl et al. 2006: 15).

20 | Die Rahmenpolitik der Weltgesundheitsorganisation bzgl. Gesundheit in der europäischen Zone (51 Staaten).

21 | Europäische ministerielle Konferenz, Istanbul, 15.-17.11.2006.

22 | Die Interviewzitate aus dem Absatz "Gesundheitsorientierung auf politischer Ebene" sind dem Expertengespräch vom 16.12.2008 mit dem zuständigen Team im Gesundheitsministerium entnommen (welches, wie in Luxemburg nicht unüblich, in verschiedenen Sprachen durchgeführt worden ist, jedoch der Lesbarkeit halber auf Deutsch wiedergegeben wird), während die Zitate aus dem Absatz "Eigenverantwortung in alltäglichen Ernäh- 
len politischen Zugang nach sich. Konkret bündelt das Gesundheitsministerium thematische und zeitlich begrenzte »Aktionen « oder »Projekte«, die von Partnerinstitutionen wie Schulen, Maisons Relais pour Enfants ${ }^{23}$, Gemeinden, aber auch von Vereinen u.Ä. lanciert und unter dem Motto GIMB durchgeführt werden. Darüber hinaus bietet das Ministerium eine Plattform für den Erfahrungsaustausch und die Vernetzung dieser »Akteure im Feld«, jedoch ohne ein systematisiertes Feedback der Ergebnisse von deren Initiativen. Umso weniger besteht ein formaler Austausch zwischen dem Ministerium und der Gesamtbevölkerung, außer über den Weg der eingeschulten Kinder. Diese sollen mit staatlich gefördertem und flächendeckend an Schulen verteiltem pädagogischen Material ${ }^{24}$ in Verbindung kommen und schließlich ihre Eltern sensibilisieren. Dieser Prozess ist - sofern er stattfindet - langfristig angelegt und auf einen gesellschaftlichen bzw. kulturellen Wandel ausgerichtet. Genau um diesen »tiefschürfenden Gewohnheitswandel« sind die Verantwortlichen des GIMB bemüht, d.h. um »Bewusstseinsmachung, die Mobilisierung, Interesse und Engagement schafft«. In den GIMB-Projekten geht es daher nicht um eine »eins-zu-eins Anwendung der ministeriellen Richtlinien, sondern um eine kreative Interpretation dessen, was in der Praxis machbar ist $\ll$.

\section{Informationskampagne für die Wohnbevölkerung}

Die Verantwortlichen des GIMB sehen sich somit in erster Linie als Impulsgeber/innen für einen langfristigen und nachhaltigen Prozess, welchen sie stop-down< über verschiedene Institutionen fördern und schließlich gesellschaftlich verankert sehen möchten. Als Pendant zu der >core activity< der ministeriellen Vergabe des Logos und des Labels GIMB für spezifische Aktionen wird die Wohnbevölkerung flächendeckend durch die Zusendung einer zweisprachigen Informationsbroschüre mit Richtlinien über gesundheitsförderndes Bewegen und Essen im Alltag informiert.

Die in unseren Interviews festgestellte Auseinandersetzung der Wohnbevölkerung mit GIMB zeigt, dass ausschließlich die o.g. Öffentlichkeitsarbeit wahrgenommen wird. Die »grüne Broschüre $\ll^{25}$ - wie die Broschüre »Freude am gesunden

rungspraxen " aus den Interviews mit Personen aus der luxemburgischen Wohnbevölkerung stammen.

23 | Eine aufgrund des großherzoglichen Reglements vom 20.07.2005 gegründete Form von Kindertagesstätten.

24 | Zusammen mit dem Bonner Verlag aid wurden unterschiedliche thematische Mappen ausgearbeitet, die sich als ansprechend, praxisnah und spielerisch verstehen. Die Umsetzung in den schulischen Alltag ist dem Lehrpersonal freigestellt.

25 | Die gewählte hellgrüne Farbe als Hintergrund für die gesamte Broschüre ist aussagekräftig, da sie einerseits Gemüse konnotiert (als Inbegriff vom Aspekt "gesond iessen", siehe auch unsere Interviewauswertung) und andererseits Natur (als Kulisse für OutdoorFreizeitaktivitäten als junge Familie bezgl. dem Aspekt "méi bewegen«). 
Essen Spaß an der Bewegung!/Le plaisir de bien manger et d'être actif!« (Ausgabe 2007) oftmals von den Interviewten bezeichnet wurde - gliedert sich in eine zweiseitige Einleitung, in Ernährungsempfehlungen, in eine Empfehlung hinsichtlich körperlicher Bewegung (anderthalb Seiten) sowie in eine Adressenübersicht zentraler Institutionen (eine halbe Seite). Der Schwerpunkt liegt mit insgesamt sieben Seiten auf der Ernährung, was vermutlich auf die zahlreichen Auswahlmöglichkeiten in diesem Bereich im Vergleich zur griffigen Maxime »Bewegen Sie sich jeden Tag wenigstens 30 Minuten« (S. 9) zurückzuführen ist.

Trotz der ernsten Hintergrundfolie der Broschüre - die falsche Ernährung und unzureichende Bewegung in statistische Korrelation mit Zivilisationskrankheiten, Krankenkassenkosten und Todesraten setzt, so dass »dringendes Handeln notwendig«(S. 1) sei - hat sich das Verfasser/-innenkollektiv um einen spielerisch-positiven und ermutigenden Tenor bemüht. Dieser wird zusätzlich von sommerlich-frischen Farben der Broschüre und lustigen Illustrationen unterstrichen. Die Empfehlungen werden weitgehend positiv formuliert, so z.B. »nehmen Sie jeden Tag Milch und Milchprodukte zu sich« (S. 5) etc. Können negative Aspekte einer Botschaft nicht umschrieben werden, so wird eine Alternative angeboten, z.B. »beschränken Sie den Konsum von fettreichen Nahrungsmitteln. Ziehen Sie pflanzliche Fette den tierischen Fetten vor« (S. 4). So existieren keine >verbotenen< Nahrungsmittel, vielmehr wird Wert auf Vielfalt und auf Nahrungsmittelzufuhr laut Ernährungspyramide gelegt, d.h. letztendlich auf die Ausrichtungen der Diätetik. ${ }^{26}$

26 | Bezeichnenderweise ist die Association Nationale des Diététicien(ne)s du Luxembourg die einzige nicht-staatliche Partnerorganisation auf nationalem Niveau, die in der Broschüre aufgeführt ist. 


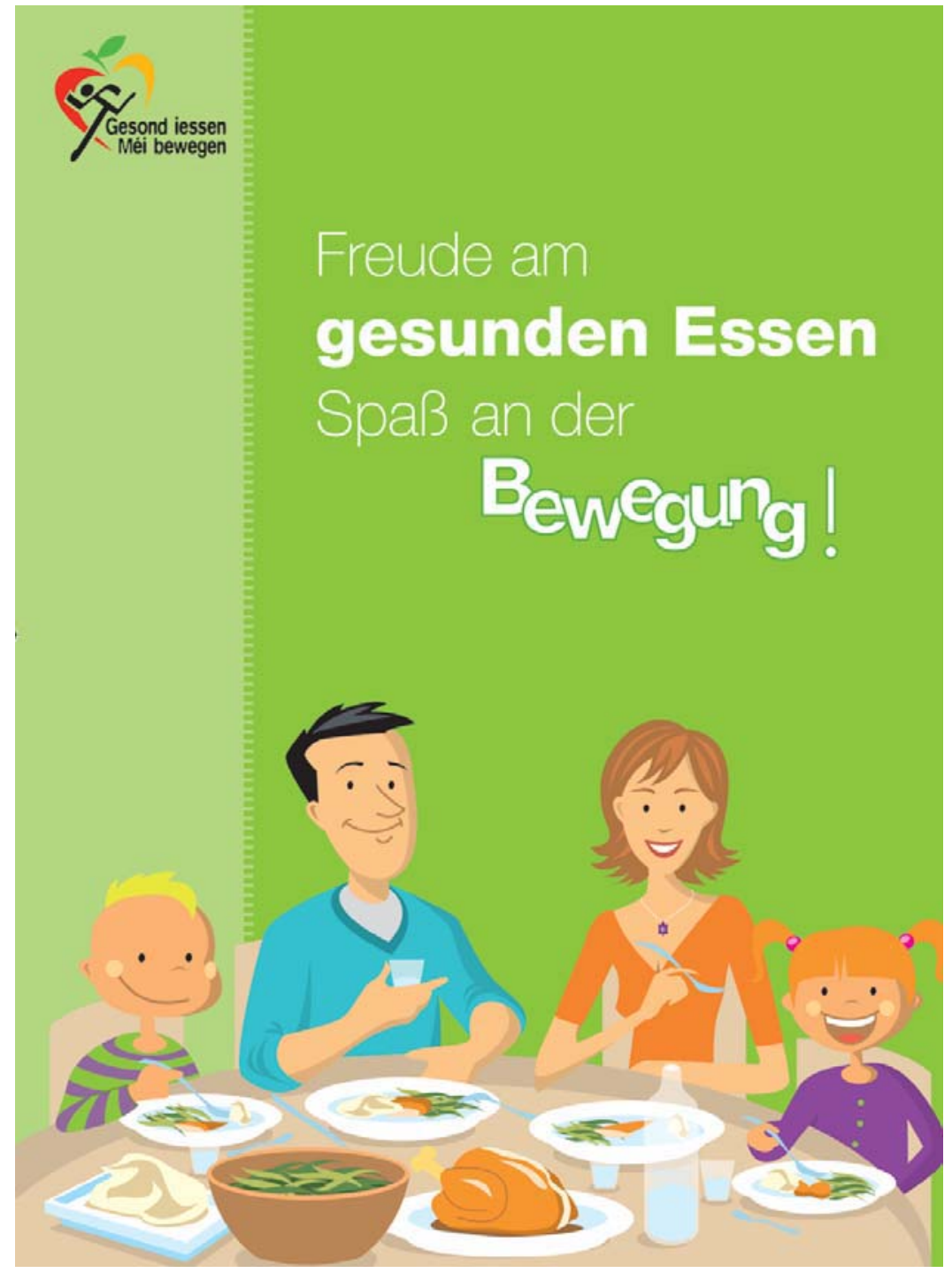

Abbildung 2: Deckblatt der Broschüre »Freude am gesunden Essen. Spaß an der Bewegung!/Le plaisir de bien manger et d'être actif!« (Ausgabe 2007)

In der Einleitung der Broschüre durch den Gesundheitsminister wird die Legitimierung der euphemistisch dargelegten Anstrengung, die die angestrebte Ernährungsumstellung mit sich bringt (»Ich wünsche Ihnen Ausdauer«), durch ein erhöhtes Selbstwertgefühl zementiert, das u.a. durch »Freude« und »Sich wohl fühlen in Ihrer Haut« herbeigeführt werden soll. So geht »Ich wünsche Ihnen Ausdauer« Hand in Hand mit dem »Spaß, neue Ess- und Bewegungsgewohnheiten zu entdecken und in Ihren Alltag aufzunehmen« (S. 1). Mit dieser Distanz schaffenden grammatikalischen Form schwingt eine Wertung mit: Ein bestimmtes >Ich< zeigt sich in einer Überlegenheitsposition, die wohlwollende Ratschläge an die Leserschaft gibt. Eine einschließende Formulierung hätte eher Solidarität und Anteilnahme artikulieren können, wie sie etwa das Verfasser/-innenkollektiv der kooperierenden Institutionen formuliert: »Lassen Sie uns gemeinsam die Wohltaten und den Spaß [...] entdecken; sie sind ein wichtiger Bestandteil unseres Wohlbefindens.« 
(S. 2) Aber auch in dieser Textpassage werden die >schlechten « Gewohnheiten - die einen staatlichen Handlungsbedarf erforderlich machen - der als Alterität konstruierten Leserschaft zugeschrieben: »Für die gute Gesundheit brauchen Sie keineswegs ganz auf Ihre Lieblingsspeisen zu verzichten. Hier erweckt eine Schein-Komplizität über das affektiv besetzte Erleben von Essen den Eindruck, die Relation zwischen Ungesundem und Bevorzugtem sei naturgemäß gegeben. Das Selbstverständnis der Broschüre lässt sich schließlich in einem Ergebnis auf den Punkt bringen, zu dem »verschiedene Studien « ${ }^{27}$ kommen: »Jeder vierte Jugendliche und jeder zweite Erwachsene leidet an Übergewicht.«(S. 2) Einerseits wird Übergewicht in dieser Aussage als ein >Leiden< dargestellt, ${ }^{28}$ dessen Existenz oder Wirksamkeit von den betroffenen Personen nicht oder wenig berücksichtigt wird. ${ }^{29}$ So haben z.B. die von uns Befragten nicht ihr Körpergewicht primär als Motivation für gesundes Essensverhalten angeführt. Sie haben vielmehr das ethische Bemühen um verantwortungsvollen Umgang mit dem eigenen Gesundheitskapital im Allgemeinen thematisiert - jedoch nicht im Sinne der Prävention von spezifischen Pathologien. Formal betrachtet stellt die radikale Zuschreibung von >Leiden< einen Bruch zum reformistisch-konstruktiven Gewohnheitswandel dar, den die Broschüre durch ein respektvolles und umsichtiges Vokabular zu vermitteln sucht. Andererseits fokussiert die o.g. Aussage auf Individuen und kommt in dieser Hinsicht dem Alltagserleben von Essen nahe. Unsere Interviews bestätigen das Empfinden der Befragten, dass die Nahrungsauswahl und -zubereitung eine zumeist individuelle und komplexe Entscheidung ist, die die Einzelperson oder auch ihr unmittelbares Umfeld betrifft (z.B. wenn sie für Familie, Mitbewohner, Gäste etc. kocht). Der Anspruch auf ausgewogenes Essen wird laut den Befragungsergebnissen tendenziell durch die Präsenz von Kindern am Familientisch erhöht. Die Broschüre trägt diesem Umstand insofern Rechnung, als die Illustrationen ausschließlich junge Familien darstellen, die implizit die wichtigste Zielgruppe bilden. Inhaltlich setzt der Fokus auf einzelne Ernährungskomponenten ${ }^{30}$ ein analytisches Wissen über Kochzutaten, Speisen- und Mahlzeitenzusammenstellung voraus - obwohl sich die ministeriellen Empfehlungen im Allgemeinen eher pragmatisch orientiert sehen und konkrete Anhaltspunkte ${ }^{31}$ liefern. So können die Empfehlungen auch andere Bevölkerungsgruppen ansprechen, wie im Folgenden zu sehen sein wird.

27 | Bemerkenswerterweise werden in der französischen Version diese wissenschaftlichen Aussagen als "faits" (S. 2) übersetzt.

28 | Eine wertungsfreiere Beschreibung hätte "[...] hat Übergewicht" sein können (obwohl auch hier ein Bezug zu einem normativen Idealwert mitschwingt).

29 | Nur für den Fall der Jugendlichen liegen die international und national durchgeführten HBSC-Studien vor, die auf diese Thematik eingehen.

30 | Obst und Gemüse, Fette, Flüssigkeit, Mehlspeisen, Milchprodukte, Salz und Zucker.

31 | Etwa dass man den ungefähren Fettgehalt einer Backware an "Fettflecken auf der Verpackung" (S. 4) einordnen kann. 


\section{Eigenverantwortung in alltäglichen Ernährungspraxen}

\section{Selektive Verinnerlichung allgemeiner Ernährungsempfehlungen}

Die Verfasser/-innen des institutionellen Identifikationsangebots GIMB begreifen >gutes< Essen als >gesundes< Essen, das vielfältig und ausgewogen ist und dessen Verzehr Freude machen soll. Das Verständnis der Interviewten weicht von diesem gesundheitsorientierten Konzept z.T. ab, bedingt durch das selektive Aufgreifen verschiedener Aspekte dieses Ansatzes unter Vernachlässigung anderer, sowie durch Erweiterungen der Kategorie des >guten< Essens um anders gelagerte, individuelle oder intersubjektive Kriterien.

Diese relativen Abweichungen lassen sich z.T. auf die Bekanntheit des GIMB zurückführen: $70 \%$ der Befragten geben an, von GIMB gehört zu haben. Von ihnen hat sich jedoch weniger als die Hälfte (43\%) aktiv damit auseinandergesetzt (vor allem aus dem liberal-gehobenen und dem alternativen Milieu, d.h. vorrangig Personen mit Hochschulabschlüssen und hohem Einkommen [5000-7000 $€$ ], meistens mit Kindern). Außerdem ist die Aufmerksamkeit für die landesweite ministerielle Informationskampagne gering: »Ich habe nicht sehr darauf geachtet«, »Also schon eng Kéier duerchgekuckt, jo mä net méi «32, »Do war mol sou e Flyer «33 oder »Ech kennen nëmmen d'Iwwerschrëft« ${ }^{34}$.

Bemerkenswerterweise verweisen die Angaben der Befragten zum täglichen und wöchentlichen Speiseplan jedoch auf eine - zumindest auf diskursiver Ebene - selektive Verinnerlichung von allgemeinen Ernährungsempfehlungen, auch wenn diese nicht spezifisch mit GIMB in Verbindung gebracht werden. Dieses Ergebnis ist nur bedingt an die betrachteten sozio-kulturellen Milieus gekoppelt; insbesondere für die Kategorien Süßigkeiten und Gebäck, Obst und Gemüse, sowie Getreideprodukte herrscht Konsens in allen Milieus (keine Abweichung vom Durchschnitt von mehr oder weniger als $5 \%$ ), und für alkoholische Getränke und Fleisch in nahezu allen Milieus (eine Abweichung von mehr oder weniger als $5 \%$ ). Die am wenigsten von soziodemografischen Variablen ${ }^{35}$ beeinflussten Nahrungskategorien - deren Konsum also gesamtgesellschaftlich am beständigsten ist - sind Milch und Milchprodukte, Getreideprodukte sowie Obst und Gemüse. ${ }^{6}$ Dementsprechend gaben $81 \%$ der Befragten als am weitesten verbreitetes Ernährungsideal an: »Leichte und kurz gegarte Gerichte machen ein gutes Essen aus«.

32 | Deutsch: "Also schon mal so durchgekuckt, ja, aber nicht mehr."

33 | Deutsch: "Da war mal so ein Flyer."

34 | Deutsch: "Ich kenne nur die Überschrift."

35 | Alter, Geschlecht, Bildung, Beruf, familiäre Situation und (Nicht-)Aktivität der Befragten.

36 | Eine detaillierte Darstellung der Ergebnisse ist an dieser Stelle nicht möglich. 


\begin{tabular}{|c|c|c|c|}
\hline Nahrungskategorie & $\begin{array}{l}\text { Gesamtanteil } \\
\qquad(a+b)\end{array}$ & Häufigste Antwort (a) & Zweithäufigste Antwort (b) \\
\hline \multicolumn{4}{|c|}{ Angaben zur täglichen Verzehrhäufigkeit } \\
\hline $\begin{array}{l}\text { Milch u. } \\
\text { Milchprodukte }\end{array}$ & $85 \%$ & zwei bis drei Mal pro Tag (43\%) & ein Mal pro Tag $(42 \%)$ \\
\hline Obst u. Gemüse & $83 \%$ & zwei bis drei Mal pro Tag (44\%) & ein Mal pro Tag (38\%) \\
\hline Alkoholische Getränke & $78 \%$ & nie $(43 \%)$ & ein Mal pro Tag (35\%) \\
\hline Wurstaufschnitt & $77 \%$ & ein Mal pro Tag (48\%) & nie $(29 \%)$ \\
\hline Salzige Snacks & $77 \%$ & nie $(52 \%)$ & ein Mal pro Tag $(25 \%)$ \\
\hline $\begin{array}{l}\text { Süßigkeiten u. } \\
\text { Gebäck }\end{array}$ & $71 \%$ & ein Mal pro Tag (56\%) & weniger als ein Mal pro Tag (15\%) \\
\hline Soft Drinks & $65 \%$ & nie (39\%) & ein Mal pro Tag $(26 \%)$ \\
\hline \multicolumn{4}{|c|}{ Angaben zur wöchentlichen Verzehrhäufigkeit } \\
\hline Getreideprodukte & $95 \%$ & $\begin{array}{l}\text { mehr als drei Mal pro Woche } \\
(78 \%)\end{array}$ & zwei bis drei Mal pro Woche (17\%) \\
\hline Fleisch & $90 \%$ & $\begin{array}{l}\text { mehr als drei Mal pro Woche } \\
(50 \%)\end{array}$ & zwei bis drei Mal pro Woche (40\%) \\
\hline Fisch & $87 \%$ & ein Mal pro Woche (57\%) & zwei bis drei Mal pro Woche (зо\%) \\
\hline Kartoffeln & $80 \%$ & zwei bis drei Mal pro Woche ( $44 \%)$ & mehr als drei Mal pro Woche (36\%) \\
\hline
\end{tabular}

Tabelle 3: Tägliche und wöchentliche Verzehrhäufigkeiten der Luxemburger Wohnbevölkerung

Auf die im Interview gestellte Frage, was in Bezug auf Ernährung wichtig sei, wird die »Ausgewogenheit« als ein zentrales Anliegen genannt, ebenso der gemäßigte Konsum von sämtlichen Nahrungsmitteln. Dies ist sicherlich der innovativste Aspekt von zeitgenössischen internationalen Ernährungskampagnen (Coveney 2006), da er sich der Essenspraxis der Interviewten annähert. Sehr oft wird das Desiderat nach »mehr Obst und Gemüse « angeführt, nur gelegentlich jedoch wird dies mit dem Schlagwort »fünf am Tag« genannt. Schließlich soll die Ernährungspraxis den Befragten zufolge »nicht zu fettig« sein, wobei sich hier das Gesundheitsbestreben mit dem machtvollen Ideal der Schlankheit überschneidet. Keine oder wenig spontane Erwähnung finden demgegenüber die spezifischen Empfehlungen bzgl. Wasser und Alkohol, Mehlspeisen, Milchprodukten, Salz und Zucker. Dieses Ausklammern geht z.T. auf den hochgradigen Alltagswert von Essen zurück, der eine gewisse Resistenz gegenüber Selbstreflexion mit sich bringt.

\section{,Doing Identity، zwischen Eigenverantwortung, Handlungspotential und Pragmatismus}

Dieses Alltagserleben hinsichtlich >gutem< Essen beinhaltet identitätsrelevante Dimensionen, die über den Rahmen der technischen Essenszubereitung (so wie er im GIMB und anderen ernährungswissenschaftlichen Ansätzen vermittelt wird) hinausgehen. Diese lassen sich in drei diskurspraktische Stränge des >Doing Identity< bündeln: 
1) Am häufigsten tritt der Diskurs der Eigenverantwortung in Erscheinung, der sich in drei Varianten untergliedert (positiv, flexibel, negativ) und unterschiedliche Ansprüche erfüllt (Subjektivation, Verantwortung für Kinder, an ethischen Vorstellungen orientierter Konsum).

In der positiven Variante stellt das alltägliche Anliegen von >gutem< Essen einen herausfordernden Handlungsspielraum dar, in dem selbstbestimmte Subjektivationen ausgetestet werden (über das eigene Kochen) und sich ausprägen können (über resultierende Präferenzen). Hier geht es darum, vieles »einfach ze probéieren «37 und ohne Schuldgefühle zu genießen (»ët soll schmaachen«, »Schëllegkeet erof $\left.«^{3}{ }^{8}\right)$. »Aimer ce qu'on mange $\ll^{39}$ wird im doppelten Sinn von Wohlgeschmack und positiver Grundeinstellung zum Essen begriffen, und die marktgängigen Wahlmöglichkeiten werden als Chance anstatt einer Selbstverständlichkeit angesehen (»mir kënnen eis kafen wat mir wëllen $\varkappa^{4 \circ}$ ).

Ich bin grundsätzlich mit meiner Ernährungsweise im Alltag zufrieden. Ja. Die hängt ja von mir ab. Wenn ich was Falsches koche, dann kann ich nicht sagen, ich bin beim Kochen nicht zufrieden." (Männlich, 50 Jahre, Luxemburger, Junglinster)

Ech passen zimlech op datt et ë bëssen gesond ass, jo vill Uebst. Ech denke mer, et kann een jo awer vill maachen fir seng Gesondheet, dat kann een nët alles den Genen iwwerloossen, ech mengen et kann een och sälwer maachen. " ${ }^{41}$ (Weiblich, 74 Jahre, Luxemburgerin, Dudelange)

Ech sin zefridden mat menger Ernährungsweis am Alldag, wëll ech éischtens mol doheem sälwer kachen, dat heescht ech sichen sälwer eraus wat ech iesse wëll. [...] Firdrun hun ech alles giess wat mir an d'Aën geflunn ass, ewourobber ech Loscht hat, an elo kucken ech vill méi drop wat ech genau iessen, zum Beispill méi Friichten, manner Schokela, nët zevill naschelen [...]. Am wichtegsten ass esou équilibréiert wéi méiglech, elo nët all Dag Nuddelen, mee esou vill wéi méiglech an verschidden ewéi méiglech an och ... jo nët ze vill Naschereien dertëschent, dat heescht datt ech wirklech ee fixe Plang hunn. ${ }^{42}$ (Weiblich, 18 Jahre, Portugiesin, Stadtbredimus)

37 | Deutsch: "einfach zu probieren".

38 | Deutsch: "es soll schmecken «; "ohne Schuldgefühle".

39 | Deutsch: "das was man isst lieben «. Die oben kommentierte Doppelbedeutung von diesem französischen Satz findet sich im Deutschen nicht wieder, wo eher "sein Essen mögen" gesagt wird.

40 | Deutsch: "wir können uns kaufen was wir wollen".

41 | Deutsch: "Ich passe ziemlich auf, dass es ein bisschen gesund ist, ja, viel Obst. Ich denke mir, man kann doch viel für seine Gesundheit tun, das kann man nicht alles den Genen überlassen, ich meine, man kann auch selbst etwas tun."

42 | Deutsch: "Ich bin zufrieden mit meiner Ernährungsweise im Alltag, weil ich erstens zu Hause mal selbst koche, das heißt, ich wähle selbst was ich essen will. [...] Vorher aß ich 
Verbreiteter jedoch als solche dezidiert voluntaristischen Positionen sind flexible Arrangements, bei denen einzelne Abweichungen toleriert werden, wenn die Gesamtbilanz subjektiv angemessen erscheint:

Ech denke mëttlerweil datt ech also net sou schlecht ..., awer bon, it sinn mol Saachen derbäi, déi net onbedéngt misste sinn. Mee bon, se sinn derbäi." ${ }^{43}$ (Weiblich, 27 Jahre, Luxemburgerin, Vianden)

Demgegenüber wird die negative Variante des Diskurses der Eigenverantwortung weitgehend mit dem Argument des »Zeitmangels«, aber auch des geschmacklichen Konservatismus hervorgebracht. Diese Legitimierungen erscheinen jedoch vielmehr als eine passive Vermeidung 44 der Komplexität von Selbsttechniken im kulinarischen Bereich, die Planung sowie >Ad-hoc<-Entscheidungen, Positionierung in einem Feld von nahezu unbegrenzten Wahlmöglichkeiten, Ideenreichtum, technischem Können und Zeiteinteilung bedeutet.

J'aimerais manger plus équilibré, plus ... disons que je n'ai pas trop le temps donc euh ... Et puis quand on mange au travail, on est toujours obligé de manger des choses qui vont vite euh ... - Et vous pensez que vous pouvez un jour changer ça? - Non je pense pas, mais pourquoi pas? Enfin, il faut se prendre peut-être le soir pour cuisiner quelque chose en avance et ramener au travail, euh je ne sais pas, j'ai pas encore trouvé la solution mais euh ... - Qu'est-ce qui l'empêche en fait? - Ben le temps, le temps. C'est que quand on rentre du travail le soir, on est fatigué ... Si, je pourrais, je pourrais ... mais il y a des jours où ça va, mais c'est pas régulier, ça peut être un jour où je vais manger très bien, vraiment, salade, légumes, tout ça, poisson, et l'autre jour ça va être catastrophe. " ${ }^{45}$ (Weiblich, 28 Jahre, Französin, Luxemburg-Stadt)

alles was mir in den Blick kam, worauf ich Lust hatte, und jetzt achte ich viel mehr darauf was ich genau esse. Zum Beispiel mehr Obst, weniger Schokolade, nicht zu viel naschen. [...] Das wichtigste ist, so ausgewogen wie möglich, also nicht jeden Tag Pasta, aber so viel wie möglich und so verschieden wie möglich und auch ... ja, nicht zu viele Naschereien dazwischen, das heißt, dass ich wirklich einen festen Plan habe."

43 | Deutsch: "Ich denke mittlerweile, dass ich mal gar nicht so schlecht ... aber gut, es sind mal Sachen dabei, die nicht unbedingt sein müssten. Aber gut, sie sind dabei."

44 | Es bliebe zu klären, inwiefern es sich hier um eine Selbsteinschätzung (mangelndes Selbstvertrauen) oder eine Überforderung (mangelnde Kompetenz) handelt.

45 | Deutsch: »|ch würde gerne ausgewogener essen, mehr ... Sagen wir, dass ich nicht viel Zeit habe, also eh ... Und wenn man auf der Arbeit isst, ist man gezwungen Zeug zu essen, das schnell geht eh ... - Und meinen Sie, dass Sie das eines Tages ändern können? - Nein, ich glaube nicht, aber warum nicht? Na ja, vielleicht muss man sich abends Zeit nehmen um etwas im Voraus zu kochen und mit zur Arbeit zu nehmen, eh ... Ich weiß nicht, ich habe die Lösung noch nicht gefunden aber eh... - Was hindert Sie daran? - Ach, die Zeit, die Zeit. Wenn man abends von der Arbeit zurückkommt, ist man müde ... Doch, ich könnte, ich 
Ausgewogen na ja ... aber wir essen jeden Tag etwas anderes, unterschiedliche Speisen, aber ... Ich könnte vielleicht schon noch einiges ändern, aber es müsste alles so in der gleichen Geschmacksrichtung liegen, die wir gewohnt sind. (Männlich, 38 Jahre, Portugiese, Consdorf)

Eine Person macht sich jedoch bewusst, dass der besagte Zeitmangel auf eine subjektive Prioritätensetzung in anderen Bereichen (insbesondere dem beruflichen) zurückzuführen ist:

Ech sinn eigentlech net zefridden mat menger Ernährungsart a -weis, wëll ech u sech wéisst, wéi ee sech gesond ze ernähren hätt a probéiere menge Kanner dat ze vermëttelen, mä mech selwer awer meeschtens sou ënner Drock setzen, datt ech mech net drun halen. ${ }^{46}$ (Weiblich, 30 Jahre, Luxemburgerin, Dippach)

Das Ideal der verantwortungsvollen Selbstregierung - ob sie nun mit einer gewissen Offenheit oder mit Zweifeln und Missmut praktiziert wird - gewinnt an Bedeutung, wenn es zusätzlich zum >Ich < an die eigenen Kinder herangetragen wird. Diese Ernährerrolle (im wörtlichen Sinn) scheint so weit verinnerlicht zu werden, dass sie auch noch im Zusammenhang mit erwachsenen Kindern als sinngebend genannt wird. Der Diskurs der notwendigen Vorbildrolle der Eltern für ihre Kinder beinhaltet insbesondere eine normative Aufwertung der Kategorie >Obst und Gemüse<.

Ech sinn zefridden mat der Art a Weis méi ech mech ernähren wëll dat bestëmmen ech jo selwer. An ech kucken wëll ech zwee Kanner hei am Stot hunn, bon deen een ass 18, dat anert ass 24 ... kucken ech awer datt bëssen Uebst a Geméis... a variabel, datt d'lessen net langweileg ass an datt se gär iessen, jo. ${ }^{47}$ (Weiblich, 53 Jahre, andere Nationalität, Lenningen)

Ich finde Suppe sehr wichtig für die Ernährung. [...] Und es ist eine gute Art, die Kinder dazu zu bringen, Gemüse zu essen. (Weiblich, 47 Jahre, Portugiesin, Putscheid)

könnte ... aber es gibt auch Tage wo es geht, aber es ist nicht regelmäßig, das kann ein Tag sein wo ich wirklich sehr gut esse, Salat, Gemüse, all' so was, Fisch, und ein anderer Tag wo es katastrophal ist."

46 | Deutsch: »|ch bin eigentlich nicht zufrieden mit meiner Ernährungsart und -weise, weil ich an sich wüsste, wie ich mich zu ernähren hätte und probiere, das meinen Kindern zu vermitteln, aber mich selbst meistens so unter Druck setze, dass ich mich nicht daran halte." 47 | Deutsch: "Ich bin zufrieden mit der Art und Weise wie ich mich ernähre, weil das bestimme ich ja selbst. Und ich schaue, weil ich zwei Kinder hier im Haushalt habe, gut, der eine ist 18, die andere ist 24 ... ich schaue aber, dass ein bisschen Obst und Gemüse ... und abwechselnd, dass das Essen nicht langweilig ist und dass sie gerne essen, ja." 
Mit der Sorge um die eigenen Kinder ist teilweise das Bestreben nach einer ethischen Konsumform verknüpft. Statistisch gesehen handelt es sich bei dieser Einstellung um ein Segment der Bevölkerung, das tendenziell den älteren Jahrgängen angehört, einen leicht erhöhten Anteil an Frauen zählt, eher zu den Nicht-Erwerbstätigen (Hausfrau/-mann, pensioniert) oder zu den Selbstständigen zählt, Kinder hat und Hochschulabschlüsse aufzeigen kann. Dieses Profil entspricht im Wesentlichen dem der Personen, die GIMB kennen und sich damit auseinandergesetzt haben - was bedeutet, dass GIMB vor allem von denjenigen rezipiert wird, deren Ernährungspraxis sich ohnehin schon an der >gewünschten< Richtung orientiert. Hier ist das als explizit verantwortungsvoll dargestellte Handeln entweder auf die Nahrungsmittel selbst gerichtet (etwa Rückverfolgbarkeit oder Qualität des Produkts) oder auf die gesamte Herstellungskette (etwa Saisonalität, Regionalität, biologische Landwirtschaft, fairer Handel oder artgerechte Tierhaltung). Da Bemühungen um Nachhaltigkeit durch einen wahrgenommenen Mehrwert für die eigene Gesundheit oder auch durch die wahrgenommene Affektivität bei der Herstellung motiviert sind - also durch identitätsrelevante Kriterien -, ist diese Haltung als ambivalent $\mathrm{zu}$ betrachten (Lamine 2008):

Ech ginn haaptsächlech an Bio Rayonen akafen. [...] Haaptsächlech Geméis muss wierklech ... do muss nach eppes dra sinn. [...] Ech sinn iwwerzeegt, datt déi industriell Nahrungsmëttel, datt do, alles wat sou ouni Léift gemaach ass, datt do wierklech just nach minimal eppes Guddes fir eis dran ass. ${ }^{48}$ (Weiblich, 41 Jahre, Luxemburgerin, Bous)

2) Ein anderer diskurspraktischer Strang ist der des >hypothetischen Handlungspotentials<; insbesondere im Fall unerwarteter Gesundheitsprobleme oder akuter Gewichtszunahme »wéisst een, wat een ze maachen hätt« ${ }^{49}$. Solange jedoch keine größeren Veränderungen feststellbar sind, herrscht Nachsichtigkeit bzgl. gelegentlichen >Ausrutschern< vor - wie auch immer diese in der Alltagspraxis definiert werden.

Fir déi Leit déi sech selwer iergendwéi iwwergewiichteg fannen oder déi selwer fannen datt se net gesond iessen ass dat vläicht ee flotten ... een Input, sou ze soen an si gesinn, okay wann jiddereen dat mécht, dann kann ech och dozou bäidroen, mee ech perséinlech, also nee. ${ }^{50}$ (Männlich, 18 Jahre, Italiener, Strassen)

48 | Deutsch: "Ich kaufe vor allem in Bioregalen ein. [...] Hauptsächlich Gemüse muss wirklich ... da muss noch was drin sein. [...] Ich bin überzeugt, dass diese industriellen Nahrungsmittel, dass da, alles was so ohne Liebe gemacht ist, dass da wirklich nur noch minimal etwas Gutes für uns drin ist."

49 | Deutsch: "wüsste man, was man zu tun hätte".

50 | Deutsch: "Für Leute, die sich selbst irgendwie übergewichtig finden oder die selbst finden, dass sie nicht gesund essen, ist das vielleicht ein netter ... Input, sozusagen und 
Diese Position kann bis hin zu einem bewusst beanspruchten Gegenentwurf reichen:

Da kuckt een dat [0.g. Broschüre], et stellt een awer keng Gedanken drop, da leet een et rëm op d'Säit. Wëll mir beweegen eis net sou gär! ${ }^{51}$ (Weiblich, 66 Jahre, Luxemburgerin, Ettelbruck)

Oftmals ist eine Dialektik zwischen einer allgemeinen und einer persönlichen Diskursebene feststellbar. Initiativen wie das GIMB (aber auch Informationen über >gutes < Essen in den Medien und in der Fachliteratur) werden als allgemein erstrebenswert angesehen, die Person selbst fühlt sich jedoch nicht davon angesprochen, so z.B.: »Ech fannen et gutt datt de Ministère eppes mécht. Ob et eppes déngt, dat ass eng aner Fro. $\ll^{52}$ Dies ist ein typisches alltagskulturelles Paradox, das nicht selten mit Humor umschifft wird. Die Ambivalenz der >Lösung< wird dadurch zwar alltagstauglich entschärft, aber nicht aufgehoben:

- Wie sind Sie auf das Programm "Gesond iessen méi bewegen" aufmerksam geworden? - Durch die Medien. - Und was halten Sie davon? - In unserer Gemeinde gibt's auch so ein Slogan ein Mal pro Jahr. Da werden die Straßen hier für den Verkehr abgesperrt und ich glaube das geht in dieselbe Richtung ${ }^{53}$. - Haben denn diese ...? - [unterbricht] Die bewegen aber leider bei mir nicht sehr viel (lacht)! (Männlich, 37 Jahre, Luxemburger, Bertrange)

3) Schließlich lässt sich vor dem Hintergrund der vorangegangenen diskurspraktischen Stränge der Pragmatismus angesichts widersprüchlicher kursierender Normen ausmachen. Dieser Pragmatismus stellt gewissermaßen das >banalste und weit verbreitetste Handlungsmuster in Bezug auf die alltägliche Ernährung dar - eben aufgrund der inhärenten Ambivalenz, die Widersprüche zwar anerkennt, sich jedoch mit ihnen arrangieren kann. Demgegenüber fungieren die >Eigenverantwortung < und das >hypothetische Handeln< eher als bewusste Positionierungen. Die Widersprüchlichkeit der Essensnormen wird ungleich intensiv wahrgenommen (von verwirrend über gleichgültig bis auffordernd). Sie kann außerdem zeitlich strukturiert sein - etwa wenn die Wertvorstellungen der (vergangenen) Essenssozialisation nicht mit denen der (aktuellen) Praktiken übereinstimmen. Die herausgearbeitete Ambivalenz kann des Weiteren ethisch orientiert sein, insbesondere

sie sehen, okay, wenn jeder das macht, dann kann ich auch dazu beitragen, aber ich persönlich, also nein."

51 | Deutsch: "Dann schaut man sich das an [0.g. Broschüre], man verschwendet aber keinen Gedanken daran, dann legt man es wieder zur Seite. Weil wir bewegen uns nicht so gerne!"

52 | Deutsch: "Ich finde es gut, dass das Ministerium etwas tut. Ob es was nützt, das ist eine andere Frage."

53 | Im Sinne eines thematischen Aktionstags, z.B. ein autofreier Sonntag. 
auf der Ebene der strukturellen Entwicklungen des Ernährungsangebots - etwa wenn die Industrialisierung der Nahrungsmittelherstellung Zweifel an deren Qualität aufkommen lässt. Sie kommt ebenso situationsbedingt zum Vorschein, vorzugsweise auf der Ebene der individuellen Konfrontation mit spezifischen Einschränkungen - etwa wenn Ernährungsempfehlungen und -angebot auseinanderklaffen. Folgendes Zitat bringt diese Dimensionen auf den Punkt:

On n'arrive jamais à vraiment ... Parce qu'en plus, la télé, les médecins, ils vous disent: "il faut manger comme ça", en plus maintenant la nourriture n'est plus aussi saine qu'avant alors ... [...] On vous dit tout le temps, on vous dit plus quoi manger que dans le temps. Je veux dire, nos parents, on leur disait toujours: "mange, finis ton assiette, mange bien", et nous on nous dit: "attention, ne mange pas trop"! [...] II faut faire plus attention. [...] Y a beaucoup plus de choix et puis d'un autre côté, on vous dit: "attention, n'en fais pas trop", alors on est un peu frustré. ${ }^{54}$ (Weiblich, 28 Jahre, Französin, Luxemburg-Stadt)

Doch unabhängig davon, wie hoch der kognitive Aufwand der Ernährungszusammenstellung ist, wird er im Alltagserleben durch eine pragmatische Fokussierung auf den kommunikativen Wert und die Vergemeinschaftung durch Essen kompensiert. So liegt das gemeinsame Essen »am Familljekrees« oder »all zesummen« vielen Interviewten am Herzen; »An Arbeitstagen ist Essen für mich eine gute Gelegenheit, mit anderen zusammen zu sein«, wurde dementsprechend von $74 \%$ der Befragten ${ }^{55}$ bejaht:

't ass einfach fir zesummen ze sinn an bëssen, jo, ze schwätzen. [...] Et schafft een, also déi eng ginn schaffen, déi aner ginn an d'Schoul, d.h. et ass ee bal ni zesummen a wéinstens ass een dann, wann een ësst, dann ass een zesummen. Et soll een och e bësse Kommunikatioun hunn. ${ }^{56}$ (Männlich, 18 Jahre, Italiener, Strassen)

54 | Deutsch: "Man bringt es nie fertig, wirklich ... Weil zusätzlich sagen dir das Fernsehen und die Ärzte: 'Man muss so und so essen. Außerdem ist das Essen heute nicht mehr so gesund wie früher, daher ... [...] Man sagt Dir dauernd, man sagt dir mehr was du essen sollst als früher. Ich will damit sagen, dass man unseren Eltern immer sagte: , $ß$, iß deinen Teller leer, iß gutı, und uns sagt man: 'Achtung, iß nicht zu vielı! [...] Man muss mehr aufpassen. [...] Man hat viel mehr Auswahl und andererseits sagt man dir: "Achtung, übertreibe nicht", dann wird man etwas frustriert."

55 | Bei dieser Einstellung sind vor allem zwei Variablen statistisch tragend: das Alter und die Erwerbstätigkeit. Insbesondere die noch nicht oder nicht mehr im Erwerbsleben Stehenden sowie die nicht Erwerbstätigen legen Wert auf diese Art der alltäglichen Geselligkeit - was wiederum bestätigt, dass die emotionale Verfügbarkeit zum Essen entscheidend ist.

56 | Deutsch: "Es ist einfach um zusammen zu sein und ein bisschen, ja, zu reden. [...] Man arbeitet, also die einen gehen zur Arbeit, die anderen gehen zur Schule, d.h. man ist fast nie 


\section{Identitäre Oszillationen}

Das angeführte Fallbeispiel hat Konvergenzen und Diskrepanzen zwischen moralischer Zuschreibung und ethischer Aneignung im Bereich des >guten< Essens - als beispielhafte Kristallisierung von identitären Konzeptionen auf politisch-institutioneller und alltagskulturell-individueller Ebene - verdeutlicht. Die prozesshafte und kreativ ausgerichtete Gesundheitsorientierung auf politischer Ebene ist praxisnah gestaltet. Indem sie ausschließlich auf das Essen selbst - seine ausgewogene Zusammenstellung und das daraus resultierende sensorische Wohlbefinden - fokussiert, behandelt sie jedoch nur den analytisch-kognitiven Teil in Bezug auf >gutes< Essen der Wohnbevölkerung. Somit spricht sie insbesondere diejenigen Personen an, die sich der Herausforderung der Eigenverantwortung sowie der Subjektivierung bei der Ernährung positiv oder flexibel stellen und über die hierfür notwendigen Kapitalien verfügen. In diesen Fällen wird, im Bereich des Essens, die Identitätsarbeit im o.g. Sinn teilweise zur Selbstverwirklichung - etwa wenn eine bewusst gewählte gesundheitsorientierte Ernährungsideologie (z.B. Vollwert-Nahrungsmittel, biologische oder biologisch-dynamische Herstellung, regionale Produkte, Vegetarismus, o.Ä.) als spezifisches, distinktives Identitätsmerkmal fungiert. Demgegenüber hat die Mehrzahl der Befragten einen pragmatischen, weniger puristischen und weniger gesundheitsorientierten Zugang zur Ernährung, die weniger objektbezogen und vielmehr personenbezogen gelebt wird. Hier stehen sowohl das subjektive - eher spontane, wenig reflektierte und gesundheitstechnisch eventuell kurzsichtige - Erleben im Vordergrund, als auch intersubjektive und kulturelle Dimensionen der Vergemeinschaftung. (Reckinger 2008) Letztere zeigt sich insbesondere als Sorge um die Kinder und als kommunikativer Zusammenhalt von >meaningful others<, d.h. als affektive und soziale Identitätsarbeit in einem umfassenderen Sinn als nur Gesundheitsorientierung. Gerade diese pragmatisch-hedonistische und personenbezogene Ausrichtung auf individueller und kollektiver Ebene wird bei dem betrachteten politischen Identifikationsangebot ausgeblendet. ${ }^{57}$ Dementsprechend ist in der Interaktion zwischen den betrachteten Zuschreibungen und Aneignungen eine permanente Oszillation auszumachen, da sich das institutionelle Regierungsbestreben im foucaultschen Sinne (hier: GIMB) und die alltagskulturellen Selbstregierungen (hier: die befragte Wohnbevölkerung) teilweise überlagern und eine permanente und grundsätzlich ambivalente Variation zulassen. Die ethische Aneignung des Ideals des 'guten< Essens kann sowohl mit den moralischen, intentionalen und korrigierenden Logiken der politischen Zuschreibung in Einklang stehen (identitäre Anpassungৎ),

zusammen und wenigstens ist man dann, wenn man isst, dann ist man zusammen. Man soll auch ein bisschen Kommunikation haben."

57 | Da das GIMB jedoch als langfristiger und gesellschaftlicher "Prozess" und nicht als "Projekt" mit sofortigen konkreten Auswirkungen angelegt ist (Wagener 2008: 25), wären Synergien in diese Richtung zukünftig nicht unmöglich. 
von ihnen abweichen (>identitäre Opposition<) oder ganz anderen Mustern folgen (>identitäre Eigenständigkeit<). Eben in dieser Dynamik liegt die Bedeutung des gewählten Fallbeispiels für die Gouvernementalitätsforschung ${ }^{8}$ bzw. für die Beleuchtung von identitätsbezogenen Konstruktionsprozessen.

\subsection{Die Grenzgänger als vertraute Fremde}

Die Hinwendung zum Grenzgängerwesen als ein weiteres illustratives Beispiel für Prozesse der Identitätsbildung liegt in seiner Entwicklung und Rolle für die luxemburgische Gesellschaft begründet. Mit insgesamt 147.400 Männern und Frauen (2009), die täglich aus dem Saarland und aus Rheinland-Pfalz (DE), aus Lothringen (FR) oder Wallonien (BE) nach Luxemburg an ihren Arbeitsplatz pendeln, zählt Luxemburg die meisten Grenzgänger in der EU-27 (European Commission 2009: 18-20).59 Darunter befinden sich zur Hälfte Franzosen und jeweils ein Viertel Belgier bzw. Deutsche. Ihre Gesamtzahl hat sich seit Ende der 1980er Jahre versechsfacht, wobei 1995 erstmals mehr Grenzgänger/-innen als ansässige Ausländer/-innen im Großherzogtum arbeiteten und 2001 die Zahl der Grenzgänger/-innen die der Arbeitnehmer/-innen mit luxemburgischer Staatsbürgerschaft überstieg. Heute (2009) beläuft sich der Anteil der Luxemburger/-innen am Arbeitsmarkt auf $29 \%$, der ansässigen Ausländer/-innen auf $27 \%$ und der Grenzgänger/-innen auf $44 \%$. Die starke Anziehungskraft des Großherzogtums ist neben weichen Faktoren (Jobadäquation, Karrierewege usw.) vor allem auf den attraktiven Nettoverdienst und das Arbeitsplatzangebot zurückzuführen. Denn im Gegensatz zu den Nachbarregionen werden in Luxemburg trotz Konjunkturtiefs mehr Jobs geschaffen als - wie zu erläutern sein wird - mit ansässigen Arbeitskräften besetzt werden können.

\section{Theoretische Annäherung an den Status der Grenzgänger}

Angesichts des seit Jahrzehnten außergewöhnlich hohen quantitativen Gewichts und der damit verbundenen Abhängigkeit von Arbeitskräften aus den Nachbarregionen stellt sich die Frage, ob den Grenzgängern in Luxemburg der Status des Fremden oder des Vertrauten zukommt. Damit stehen hier die Wahrnehmungen

58 | Nach Foucault (1993; 1984b; 1983; 1982a; 1982b; 1978; vgl. auch Bröckling/Krasmann/Lemke [2000]) setzt sich dieser Neologismus aus 'Gouverner, (Regieren) und 'Mentalité، (Denkweise) zusammen und ermöglicht eine simultane und relationale Lesart auf kollektive und individuelle Formen der identitären Regierung - in Form von moralischen und politischen Rationalitäten ebenso wie von ethischen und individuellen Selbsttechniken. So konvergiert staatliche Kontrolle mit Selbstkontrolle - diese Konvergenz ist jedoch fundamental dynamisch und veränderbar, wie vorliegendes Fallbeispiel aufzeigt.

59 | Lediglich in der Schweiz arbeiten mehr Grenzgänger aus den benachbarten Ländern. 
des Grenzgängerwesens durch die Luxemburger Wohnbevölkerung im Vordergrund, welche verschiedene Formen der Aneignung bzw. der Konstruktion des Grenzgängerwesens repräsentieren. Die Beschäftigung mit dem Fremden führt auf theoretischer Ebene zunächst zu jener soziologischen Richtung, die Stichweh als »klassische Soziologie des Fremden« bezeichnet (Stichweh 2005). Dabei handelt es sich um den »Exkurs über den Fremden« von Georg Simmel, der den Fremden als Wanderer mit einer sozialen Gemeinschaft in Beziehung setzt. Er unterscheidet zwischen den Konsequenzen für die aufnehmende Gemeinschaft und der Beobachtung derselben aus der Perspektive des Fremden. (Simmel 1908) Diese Positionierungen werden von Robert Park im Konzept des >marginal man< erweitert, welcher sich auf der Grenze zwischen zwei Kulturen befindet und Ressourcen entwickeln muss, um einen Kulturkonflikt zu lösen. (Park 1974) Schließlich fragt Alfred Schütz in handlungstheoretischer Perspektive nach den psychischen Prozessen, die der Fremde zu bewältigen hat, wenn er sich in ein Feld unvertrauter Zivilisationsmuster begibt. (Schütz 1971) Ebenso wie Park misst Schütz den Status des Fremden daran, ob ihm die Übernahme der in der aufnehmenden Gemeinschaft geltenden Regeln gelingt oder ob er als Fremder weder zu seiner alten noch zu seiner neuen Umgebung gehört. Die Gemeinsamkeit dieser Ansätze besteht darin, dass sie im Fremden jeweils einen >Eindringling < in eine Gesellschaft sehen, die als normativ integrierter Verband beschrieben wird. Diese Vorstellung von homogenen Ingroups, die für Outsider nur schwer zugänglich sind, geht vermutlich auf den Erfahrungshorizont unidirektionaler und dauerhafter Migration im 19. und 20. Jahrhundert zurück und lässt sich mit der dichotomen Denkfigur >Vertrauter/Fremder < auf den Begriff bringen. Mit Blick auf das Grenzgängerwesen als eine zirkuläre Mobilitätsform würde dies bedeuten, dass die Frage nach seinem Status über die normbezogene Zugehörigkeit gelöst werden könnte. Somit wären Grenzgänger als > vertraute Insider<, welche das normative Regelwerk der luxemburger Gesellschaft beherrschen, oder als >fremde Outsider < bestimmbar.

Im Zuge der Ausdehnung transnationaler Lebenswirklichkeiten (Pries 2008; Kreutzer/Roth 2006), zu deren Akteuren auch die Grenzgänger/-innen zählen, greift die auf normbezogene Zugehörigkeit beruhende Denkfigur jedoch zu kurz. Vielmehr ist zu hinterfragen, »um welche Modalitäten es sich eigentlich handelt, in denen jemand als Fremder erfahren werden kann« (vgl. Stichweh 2005: 141). Die Frage nach dem Fremden kann sich in transnationaler Perspektive also nicht mehr an nationale Superkollektive und an die der Normenübernahme unterworfenen >Eindringlinge < richten, sondern sie muss auf die von den Ansässigen vollzogenen Konstruktionen des Fremden bzw. Vertrauten fokussieren. Denn soll die Perspektive der normativ integrierten Gesellschaften aufgebrochen und das Fremde sich auch im spätmodernen Alltag als theoretische Kategorie behaupten, so ist nach den Prozessen zu fragen, die soziale Phänomene als fremd bzw. als vertraut konstruieren. Hinsichtlich der Grenzgänger/-innen muss es also darum gehen, ihren Status anhand der Aneignungen bzw. Wahrnehmungen der Luxemburger Wohnbevölkerung zu bestimmen. Konzeptionelle Anhaltspunkte hierfür liefert der An- 
satz Armin Nassehis, der die Dichotomie der positiven und negativen Aneignung (+/-) von sozialen Phänomenen einführt. (Nassehi 1995) Damit kann das Vertraute - als Kehrseite des Fremdem - zweifach besetzt werden: positiv und negativ. Dieser theoretische Zugang, der mit dem Denkmodell >Vertrauter (+/-)/Fremder < wiedergegeben werden kann, macht Formen der gesellschaftlichen Binnendifferenzierung greifbar. Andererseits behält das Denkmodell die Kategorie des Fremden bei, welche soziale Phänomene auffängt, die sich der positiven oder negativen Aneignung durch die Subjekte verweigern und damit außerhalb des Vertrauten anzusiedeln sind. Mit Blick auf den Status des Grenzgängerwesens bedeutet dies, dass der Grenzgänger als Vertrauter bestimmt werden kann, wenn die durch die Wohnbevölkerung vollzogenen Aneignungen positiv oder negativ ausfallen. Als Fremder wäre er zu bestimmen, wenn die entsprechenden Aneignungen ambivalent anzunehmen sind, d.h., wenn sich die Wohnbevölkerung positiv und negativ gegenüber dem Grenzgängerwesen positioniert. Solche Aneignungsprozesse des Fremden oder Vertrauten werden in allen Gesellschaften praktiziert, sind sie doch auf identitätskonstitutive Differenzsetzungen angewiesen, die im Alltag durch Inklusion (positive Aneignung) und Exklusion (negative Aneignung) realisiert werden. Angesprochen sind damit ein- und ausschließende Praxisstrategien, die als Formen der alltagsdiskursiven Aneignung über spezifische Semantiken kollektive Identitäten konstruieren. Vor diesem Hintergrund werden die Aneignungsprozesse der Wohnbevölkerung im Hinblick auf das Grenzgängerwesen näher betrachtet.

\section{Alltagsdiskursive Aneignungen zwischen 'Unverzichtbarkeitı und 'Bedrohung,}

Durch die erläuterte Entwicklung des Luxemburger Arbeitsmarkts rücken die Grenzgänger/-innen zunehmend in den Wahrnehmungsfokus der Wohnbevölkerung. Die Befragten sind der Überzeugung, dass das Grenzgängerwesen im Vergleich zu den 1980er Jahren heute stärker in Alltagsdiskursen thematisiert wird. Dabei geht es um die größere Präsenz der Pendler/-innen und hiermit verbunden um die Verdichtung von Themen wie etwa Arbeitsplatzkonkurrenz oder Sprachkontakt. Ferner wird angemerkt, dass Grenzgänger/-innen zunehmend als Projektionsfläche für soziale Unzufriedenheit dienen, oder wie ein Befragter es formuliert: »Et gëtt ee gesicht, dee schold ass. ${ }^{60}$ Die folgenden Einblicke in Aneignungsstrategien hinsichtlich des Grenzgängerwesens berühren Aspekte der Wirtschaft und des Arbeitsmarkts sowie der Sprache und Kultur in Luxemburg. In den Befragungen wurden jeweils positive und negative Implikationen der Grenzgängerbeschäftigung angesprochen, um Anschlüsse an das erläuterte Denkmodell herzustellen.

Zunächst soll untersucht werden, welche Aneignungen des Grenzgängerwesens in sozio-ökonomischer Hinsicht auszumachen sind. Hierfür wurde gefragt,

60 | Deutsch: "Es wird jemand gesucht, der Schuld ist." 
ob Grenzgänger/-innen notwendig seien für die Wirtschaft Luxemburgs, und mit $87 \%$ Zustimmung ist zunächst eine positiv-einschließende Haltung gegenüber den Pendlern/-innen festzustellen. Diese basiert auf zwei Einschlussstrategien: Zum einen handelt es sich um die nützliche Arbeitskraft der Grenzgänger/-innen, die unter dem Gesichtspunkt der unzureichenden ansässigen Arbeitskräfte und der nachgefragten Qualifikationen, über die Luxemburger/-innen nur teilweise verfügen, thematisiert wird. Hintergrund dafür ist das Wirtschaftswachstum Luxemburgs, das ohne die Grenzgänger/-innen nicht möglich (gewesen) wäre. So werden seit einigen Jahren rund zwei Drittel der jährlich neu geschaffenen Arbeitsplätze mit Grenzgängern besetzt, womit nicht nur Arbeitskräfte, sondern ebenso die nachgefragten Qualifikationen ins Land geholt werden.

Dat fannen ech ganz richteg, well mir hu jo eendeiteg net genuch Leit, déi schaffe ginn; an menger Usiicht no, wa mir keng Grenzgänger hätten, hätte mir vill méi Problemer hei zu Lëtzebuerg. Da giff eis Economie och guer net fonctionnéieren; an vu que datt mir awer déi Grenzgänger hunn, hu mer eng Chance fir ze fonctionnéieren, respektiv, wat elo mat der Finanzkrise kënnt, weess ee jo awer net; also, mä et sinn och vill Lëtzebuerger, déi einfach ... bon, et wäert sécher alt, gesot: ze liddereg si fir schaffen ze goen; respektiv, si hunn einfach näischt geléiert, dat heescht si hunn op der 9ième opgehal, an ... .Oh mir kréie jo eng Plaz،. Mee haut kriss Du keng Plaz méi ouni, a mëttlerweil hunn d'Grenzgänger zimlech vill Chancen, well si awer vill méi Ausbildung hunn, wéi esou munnechen Lëtzebuerger. ${ }^{61}$ (Weiblich, 18 Jahre, Luxemburgerin, Heinerscheid)

Die zweite Einschlussstrategie hebt ebenso auf die Unverzichtbarkeit der Grenzgänger/-innen ab, jedoch erfahren sie hier keine direkte Aufwertung. Ihre Unverzichtbarkeit leitet sich den Befragten zufolge hier aus Tätigkeiten ab, die Luxemburger nicht übernehmen möchten. Sie bringen es auf den Begriff mit »Luxemburger seien sich zu fein«, »wollen sich nicht die Hände schmutzig machen«, weshalb die Grenzgänger/-innen für »Drecksarbeiten « gebraucht werden. Ebenfalls wird angesprochen, dass Grenzgänger/-innen insbesondere für niedrig bezahlte Tätigkeiten unverzichtbar seien, die von Luxemburger/-innen abgelehnt werden.

61 Deutsch: "Das finde ich ganz richtig, weil wir hier ja eindeutig nicht genug Leute haben, die arbeiten gehen; meiner Ansicht nach, wenn wir keine Grenzgänger hätten, hätten wir hier in Luxemburg viel mehr Probleme. Dann würde die Wirtschaft auch gar nicht funktionieren; aber da wir die Grenzgänger haben, kann das funktionieren; beziehungsweise was jetzt passiert nach der Finanzkrise, weiß man noch nicht ...; also, es gibt auch viele Luxemburger, die ... ja, man kann schon sagen, die einfach zu faul sind arbeiten zu gehen; ... beziehungsweise die haben einfach nichts gelernt, die haben nach der 9 . Klasse die Schule beendet und... Ja, wir kriegen schon einen Job.، Aber heute kriegst du keinen Job mehr ohne, und mittlerweile haben die Grenzgänger ziemlich viele Chancen, weil sie eine bessere Ausbildung haben als so mancher Luxemburger." 
An et sinn der och vill, wou verschidde Lëtzebuerger sech ze gutt sinn, fir déi ze maachen. ... Also, di Drecksaarbechten. Wann dat net bei der Gemeng ass oder esou, da si vill Lëtzebuerger, déi soen: "Oh nee dofir ginn ech awer net schaffen". Also do kennen ech der awer och, déi dat gesot hunn. Oder: „Fir déi Paie ginn ech net."62 (Weiblich, 31 Jahre, Luxemburgerin, Rambrouch)

So wie die Qualifikationen der Grenzgänger/-innen und ihre Arbeitskraft für niedrig vergütete Jobs betont werden, sehen die Befragten darin ebenso einen Wettbewerbsvorteil gegenüber Luxemburger/-innen. Das bedeutet, im Alltagsdiskurs werden ebenso ausschließende Strategien praktiziert, die sich unter dem Stichwort der >Arbeitsplatzkonkurrenz< fassen lassen. So sind ein Drittel (34\%) der Wohnbevölkerung der Meinung, Grenzgänger/-innen nähmen den Luxemburger/-innen die Arbeitsplätze weg und aktivieren in diesem Zusammenhang verschiedene Ausschlussstrategien. Argumentiert wird mit der wachsenden Zahl der Arbeitslosen, die anstelle der Grenzgänger/-innen beschäftigt werden sollten, und mit dem niedrigeren Lohnniveau der Grenzgänger/-innen, das die Luxemburger/innen mit ihren Gehaltsvorstellungen vom Arbeitsmarkt verdränge. Ferner wird auf das Bild der Grenzgänger als »motivierte Arbeitnehmer« verwiesen, das für viele Arbeitgeber/-innen bestimmend und zum Nachteil der Luxemburger sei. Des Weiteren wird mehrfach von der »Grenzgängerisierung « von Unternehmen berichtet, in deren Zusammenhang die Einführung von »Luxemburger-Quoten« vorgeschlagen wird. Besonders ansässige Ausländer/-innen unterstreichen das Konkurrenzverhältnis mit Grenzgänger/-innen und beklagen, dass diese ebenso wenig Luxemburgisch sprächen, aber dennoch einen weitaus besseren Zugang zum Arbeitsmarkt bekommen. Hintergrund hierfür sind strukturell bedingte Selektionsmechanismen des luxemburgischen Bildungssystems und die seit 2001 steigende Arbeitslosigkeit, von der besonders Ausländer, Jugendliche und Frauen betroffen sind. (Statec 2009a: 108)

Sie könnten ja auch die Zahl der Grenzgänger irgendwie begrenzen, statt 130.000 hereinzulassen ..., wenn das so weitergeht und immer mehr Leute hereingelassen werden, dann sieht es in Luxemburg bald nicht mehr so gut aus, so ist die Lage. ... Ein Portugiese kann praktisch nicht mehr hierher kommen, wenn er kein Luxemburgisch kann, und die anderen können doch erst recht kein Luxemburgisch; warum sollen die also herkommen dürfen und wir nicht? Die Deutschen können auch kein Luxemburgisch und kommen hierher und arbeiten für die Kommunen. In diesen Fällen finde ich das nicht in Ordnung. Warum sollen die denn herkommen dürfen ...?" (Männlich, 38 Jahre, Portugiese, Consdorf)

62 | Deutsch: "Es gibt auch viele Luxemburger, die sich zu fein sind für bestimmte Arbeiten. ... Also für die Drecksarbeiten. Wenn die nicht bei der Kommune arbeiten können ... da sind viele Luxemburger, die sagen [dann zu einem]: 'Oh nein, für das Gehalt gehe ich aber nicht arbeiten. ' Also, da kenne ich auch welche. Oder: 'Für die Kohle gehe ich nicht los.'“ 
Bereits seit den 1990er Jahren ist auch auf handlungspraktischer Ebene eine Ausschlussstrategie erkennbar, welche eine Segmentierung des Arbeitsmarkts zur Folge hat. Dabei handelt es sich um die Tendenz, dass Arbeitnehmer/-innen mit Luxemburger Staatsbürgerschaft sich zunehmend aus dem privatwirtschaftlichen Sektor auf Arbeitsplätze im öffentlichen und halböffentlichen Sektor zurückziehen. (Vgl. Statec 2009b) Diese sind nicht nur arbeits- und sozialrechtlich attraktiv, ebenso bieten sie >Schutz< vor der Konkurrenz ausländischer Arbeitskräfte. Diese von Fehlen und Pigeron-Piroth (2009) als »Rückzugsstrategie« bezeichnete Entwicklung wird durch ein »nationales Verankerungskapital« möglich, zu dem neben der luxemburger Staatsbürgerschaft entsprechende Sprachkenntnisse, sozio-kulturelles Wissen und soziale Netzwerke im Land zählen, über die Grenzgänger/-innen i.d.R. nur eingeschränkt verfügen.

[Le secteur public] constitue une sorte de refuge, dans lequel les salariés luxembourgeois peuvent faire valoir leurs compétences particulières (notamment linguistiques) qui sont raréfiées sur le marché. Il se trouve ainsi à l'abri de la concurrence des travailleurs étrangers, de plus en plus nombreux et qualifiés. (Fehlen/Pigeron-Piroth 2009: 11)

Weiterführend sollen auf sozio-kulturellem Gebiet die Aneignungen mit Blick auf das Grenzgängerwesen hinsichtlich der luxemburgischen Kultur und Sprache betrachtet werden. Hierfür wurde der Wohnbevölkerung die Frage gestellt, ob Grenzgänger/-innen eine Bereicherung für die luxemburgische Kultur seien. Über die Hälfte der Befragten (55\%) ist dieser Ansicht, wobei hier noch von Effekten sozialer Erwünschtheit auszugehen ist. Denn der damit artikulierte Einschluss von Grenzgängern/-innen in die Sphäre des Vertrauten entspricht zunächst einem öffentlichen Diskurs, ${ }^{6}$ der besonders im Umfeld des Grenzgängerfestes im Jahr 2008 wirksam wurde. So heißt es in einer Pressemitteilung des Ministeriums für Kultur, Hochschulbildung und Forschung:

Unter dem Motto ¿Zusammen arbeiten, zusammen feiern, zusammen leben، hat das Fest zum Ziel, über die Arbeitsbeziehungen hinaus und außerhalb der Bürozeiten, einen echten interkulturellen Dialog und einen gemeinschaftlichen Geist zwischen Grenzgängern und Anwohnern, sowie unter den Grenzbewohnern selbst zu fördern. Das Fest der Grenzgänger hofft so ebenfalls zur Entwicklung einer gemeinsamen regionalen Identität beizutragen. [...] Für Luxemburg als 'Land der 100 Nationalitäten ist die Vielfalt kein leeres Wort, und das Fest der Grenzgänger ist dazu berufen keine einmalige Initiative zu bleiben. (Ministerium für Kultur, Hochschulbildung und Forschung 2008: 1)

Im Gegensatz zu dieser einschließenden Strategie der Identitätszuschreibung werden im Rahmen der Interviews negative Aneignungen des Grenzgängerwesens deutlich. Hier wird Vertrautes durch identitätskonstitutive Differenzsetzungen

63 | Vgl. auch Abschnitt 5.5. 
konstruiert, wenn gefordert wird, dass die Grenzgänger/-innen sich an die luxemburgische Kultur anpassen bzw. den Luxemburger/-innen mehr Interesse und Respekt entgegenbringen sollten.

Et ass och fir mech een wichtegen Aspekt datt Frontalieren, wann se an Lëtzebuerg kommen, datt se net nëmmen heihinner kommen fir ze schaffen, mä datt se sech wéinstens e bëssen fir eis Kultur souzesoen interesséieren an och vläicht iergendwéi een Austausch oder kommunizéieren mat den Lëtzebuerger. Et sinn wierklech vill Frontalieren, déi gesinn Lëtzebuerg nëmmen als Staat, wou een Suen verdéngt; d.h. si kommen heihinner, si schaffen dann ginn si nees zeréck an si interesséieren sech guer net. Dat fannen ech ëmmer e bëssen blöd. Leit, déi awer dann heihinner kommen an vläicht dann eben sech integréieren an eis Gesellschaft dat fannen ech dann besser an wann si dann och nach versichen e bëssen Lëtzebuergesch ze schwätzen an dann fannen ech dat och gutt. ${ }^{64}$ (Männlich, 18 Jahre, Italiener, Strassen)

Wie im Zitat angedeutet wird auch mit Blick auf die luxemburgische Sprache eine ausschließende Aneignungspraxis vollzogen. Diese artikuliert sich in der Meinung, Grenzgänger/-innen seien eine Bedrohung für die luxemburgische Sprache (57\%) und setzt sich fort in der Aussage, Grenzgänger/-innen sollten Luxemburgisch zumindest verstehen können (86 \%). ${ }^{65}$ Die Befragten berichten, dass sie im öffentlichen Raum - insbesondere im Einzelhandel, Gaststättengewerbe und Gesundheitswesen - nicht in Luxemburgisch kommunizieren können ${ }^{66}$ und führen an, dass es selbstverständlich sei, im Ausland auch die landesübliche Sprache womit hier ausschließlich das Luxemburgische angesprochen wird - zu beherrschen. Dabei wird kein hohes Sprachniveau von Grenzgängern erwartet, jedoch sollte eine elementare Sprachkompetenz vorhanden sein bzw. reiche es aus, einen »guten Willen zu zeigen«.

Ech fannen et ganz schlëmm, datt een am 'Cactus، [luxemburgische Supermarktkette], op lëtzebuergesch keng Wirschtecher méi bestelle kann, well si een net verstinn. Also, ech

64 | Deutsch: "Das ist auch für mich ein wichtiger Aspekt, dass die Grenzgänger, wenn sie nach Luxemburg kommen, nicht nur hierher kommen zum Arbeiten, sondern dass sie sich wenigstens ein bisschen für unsere Kultur interessieren, oder dass sie sich vielleicht irgendwie mit Luxemburgern austauschen oder kommunizieren. Es gibt wirklich viele Grenzgänger, die sehen Luxemburg als Staat, wo sie Geld verdienen können; d.h. sie kommen hierher, sie arbeiten und dann fahren sie wieder nach Hause und haben überhaupt gar kein Interesse [am Land]. Das finde ich immer ein bisschen blöd. Leute, die aber hierher kommen und sich dann vielleicht in unsere Gesellschaft integrieren, das finde ich dann besser. Wenn die dann noch versuchen ein bisschen Luxemburgisch zu sprechen, das finde ich dann auch gut."

65 | Vgl. auch Abschnitt 4.2.

66 | Vgl. auch Abschnitt 4.3. 
fannen ee Minimum vu Sprooch missten si awer kënnen, well wa mir an d'Ausland ginn, do kënne mer och net soen 'Hei, mir si Lëtzebuerger, mir kommen, hei schwätzt emol lëtzebuergesch mat eis. ${ }^{67}$ (Weiblich, 31 Jahre, Luxemburgerin, Rambrouch)

Die oben vorgenommene Differenzsetzung zwischen Personen, die Luxemburgisch beherrschen und jenen, die über keine Luxemburgischkenntnisse verfügen, sowie die gleichzeitig eingeräumte Relativierung der Sprachkompetenzen lassen erkennen, dass das Luxemburgische im Kontext des Grenzgängerwesens primär als Identitätsmarkierung (Lüdi 2008: 187, 190), denn als effektives Kommunikationsmittel fungiert. Dies spiegelt sich z.T. ebenso in den Sprachverwendungsstrategien der Befragten wider, die sich hinsichtlich des Sprachkontakts mit Grenzgänger/-innen in vier Typen untergliedern lassen:

- Die Konfrontativen versuchen strategisch ausschließend Luxemburgisch mit Grenzgänger/-innen zu sprechen und verlassen beispielsweise ein Geschäft, wenn ihnen mit »En français, s'il vous plaît« oder »Comment? « erwidert wird.

- Die Konstruktiven hingegen räumen ein, dass Grenzgänger/-innen kein Luxemburgisch lernen können, wenn die Wohnbevölkerung die Sprachen der Grenzgänger/-innen aktiv spricht. Somit handeln sie einschließend und sprechen auch in schwierigen Gesprächssituationen luxemburgisch, wenn sie bemerken, dass sich Verkäufer/-innen oder Kellner/-innen »Mühe geben«.

- Die Pragmatiker bleiben ausschließend und sprechen apriori Französisch, da sie in dieser Verkehrssprache ihr kommunikatives Ziel erfahrungsgemäß erreichen.

- Schließlich bleiben die Vermittelnden, die sprachliche Informationen im Rahmen der Begrüßung oder im Gespräch mit einem anderen Kunden/Gast/Patienten aufnehmen und sich dann strategisch einschließend dem Verkäufer/ Kellner/Pfleger sprachlich anpassen.

Die Gesamtschau der Ergebnisse zeigt, dass die Luxemburger Wohnbevölkerung sowohl positiv-einschließende als auch negativ-ausschließende Strategien hinsichtlich des Grenzgängerwesens praktiziert. Auf Basis der quantitativen Daten kann weiterführend gefragt werden, welche Strategien in welchem gesellschaftlichen Feld aktiviert werden. Somit geht es um die übergreifende Betrachtung von sozio-kulturellen und sozio-ökonomischen Aspekten, wofür die jeweils positiven bzw. negativen Aussagen über das Grenzgängerwesen zusammengeführt werden (Tab. 4).

67 | Deutsch: "Ich finde es ganz schlimm, dass man im 'Cactus، [luxemburgischer Supermarkt] auf Luxemburgisch keine Würstchen mehr bestellen kann, weil sie einen dort nicht verstehen. Also, ich finde, die Grundlagen der Sprache sollten die aber kennen; weil wenn wir ins Ausland fahren, können wir auch nicht sagen wir sind Luxemburger, wir kommen jetzt, sprecht mal Luxemburgisch mit uns."' 


\begin{tabular}{|c|c|c|c|}
\hline \multicolumn{2}{|c|}{ Positive Aneignung (+) } & \multicolumn{2}{|c|}{ Negative Aneignung (-) } \\
\hline $\begin{array}{l}\text { sozio-kulturelles } \\
\text { Feld }\end{array}$ & $\begin{array}{l}\text { sozio-ökonomisches } \\
\text { Feld }\end{array}$ & $\begin{array}{l}\text { sozio-kulturelles } \\
\text { Feld }\end{array}$ & $\begin{array}{c}\text { sozio-ökonomisches } \\
\text { Feld }\end{array}$ \\
\hline $\begin{array}{l}\text { Grenzgänger sind } \\
\text { eine Bereicherung für } \\
\text { die luxemburgische } \\
\text { Kultur. }\end{array}$ & $\begin{array}{l}\text { Grenzgänger werden } \\
\text { in der luxemburgi- } \\
\text { schen Wirtschaft } \\
\text { gebraucht. }\end{array}$ & $\begin{array}{l}\text { Grenzgänger sind } \\
\text { eine Bedrohung für } \\
\text { die luxemburgische } \\
\text { Sprache. }\end{array}$ & $\begin{array}{l}\text { Grenzgänger } \\
\text { nehmen den Luxem- } \\
\text { burgern die Arbeits- } \\
\text { plätze weg. }\end{array}$ \\
\hline $55 \%$ (Zustimmung) & $87 \%$ (Zustimmung) & 57 \% (Zustimmung) & 34 \% (Zustimmung) \\
\hline
\end{tabular}

Tabelle 4: Positive und negative Aneignungsstrategien der Luxemburger Wohnbevölkerung

Hinsichtlich der positiv-einschließenden Aneignungsstrategie ist festzuhalten, dass diese von der Luxemburger Wohnbevölkerung vor allem im sozio-ökonomischen Feld praktiziert wird, etwa wenn es um die Unverzichtbarkeit der Grenzgänger/-innen für das nationale Wirtschaftswachstum $(87 \%)$ im Vergleich zur kulturellen Bereicherung Luxemburgs (55\%) geht. Negativ-ausschließende Aneignungsstrategien hingegen werden besonders im sozio-kulturellen Feld wirksam, etwa wenn die Frage nach der Bedrohung der eigenen Sprache durch Grenzgänger/-innen (57\%) im Vergleich zur Arbeitsplatzkonkurrenz (34 \%) gestellt wird. Diese Betrachtung gibt jedoch nur erste Hinweise auf die praktizierten Aneignungen nach gesellschaftlichen Feldern und erlaubt keine Aussagen über mögliche ambivalente Aneignungsstrategien oder über den Status des Grenzgängerwesens in sozio-kulturellen Milieus.

\section{Zum Status der Grenzgänger in sozio-kulturellen Milieus}

In Anknüpfung an die erläuterte Denkfigur >Vertrauter (+/-)/Fremder< wird im Folgenden der Status der Grenzgänger/-innen anhand der Aneignungsstrategien der Luxemburger Wohnbevölkerung bzw. in sozio-kulturellen Milieus systematisiert. Die Betrachtungen stützen sich auf quantitative Befragungsergebnisse und verweisen auf drei zentrale Status der Grenzgänger/-innen in Luxemburg. 


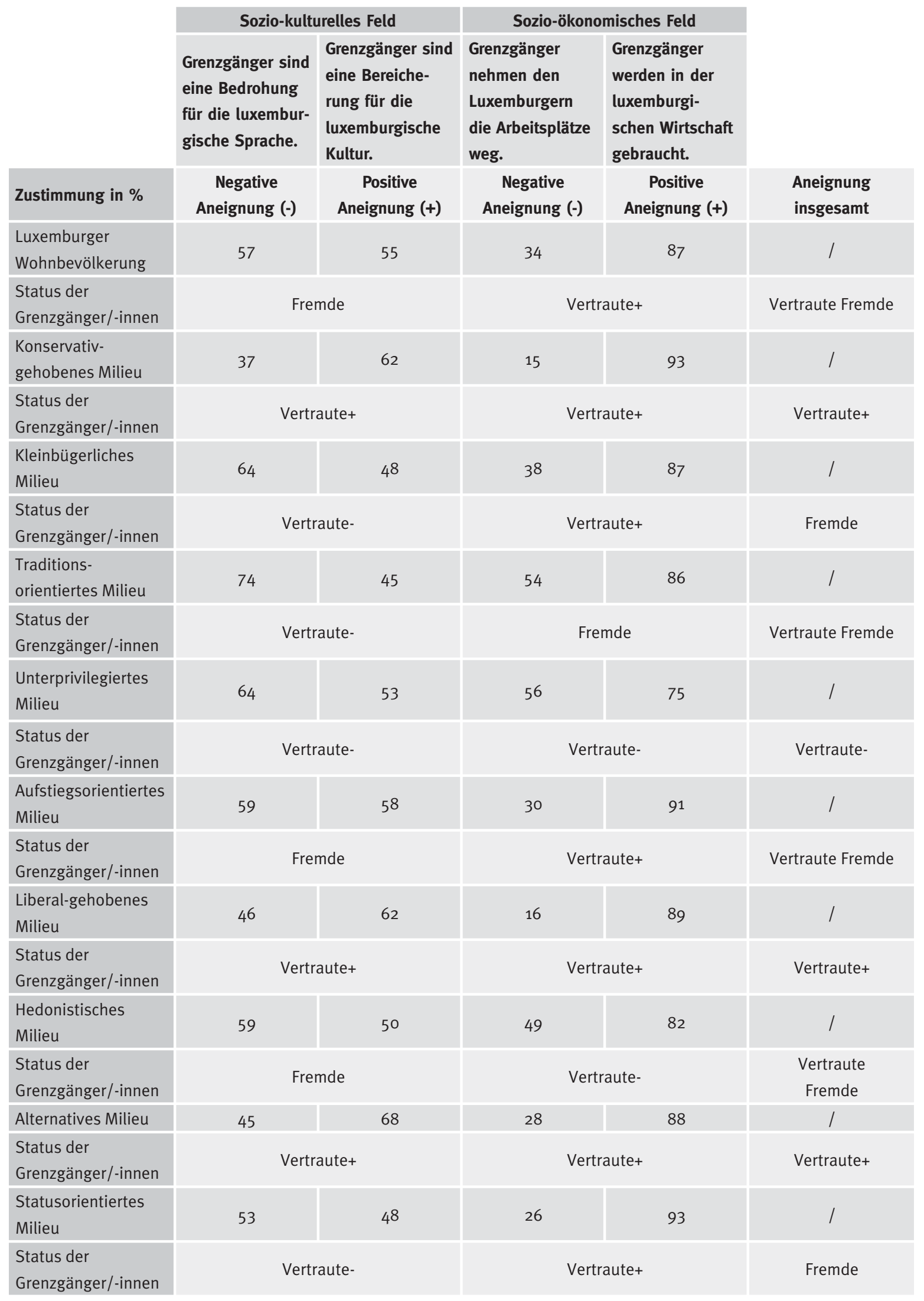

Tabelle 5: Status der Grenzgänger in sozio-kulturellen Milieus 
Grenzgänger als Vertraute: Die Aneignung der Grenzgänger/-innen als Vertraute basiert auf einer eindeutigen positiven oder negativen Konstruktion des Phänomens. Werden die Grenzgänger/-innen als >negative Vertraute< angeeignet - wie im unterprivilegierten Milieu -, so sind im sozio-kulturellen und sozio-ökonomischen Feld weitgehend negativ-ausschließende Aneignungsstrategien vorzufinden. Diese artikulieren sich im letztgenannten Feld über die Betonung der Arbeitsmarktkonkurrenz und über die Relativierung der Notwendigkeit von Grenzgänger/-innen. Hinsichtlich der Aneignung der Grenzgänger/-innen als >positive Vertraute< - die im konservativ-gehobenen, liberal-gehobenen und alternativen Milieu vorherrscht - überwiegen in den betrachteten Feldern jeweils positiv-einschließende Strategien, die über die Betonung der positiven und über die Relativierung der negativen Implikationen der Grenzgängerbeschäftigung deutlich werden.

Grenzgänger als Fremde: Die Aneignung der Grenzgänger/-innen als Fremde basiert auf einer ambivalenten Konstruktion des Phänomens. Das bedeutet, dass die Befragten sowohl positive als auch negative Aneignungsstrategien im Hinblick auf das Grenzgängerwesen praktizieren. Diese Form der Aneignung trifft auf das kleinbürgerliche und statusorientierte Milieu zu, die sich in sozio-kultureller Hinsicht eher ausschließend und in sozio-ökonomischer Hinsicht eher einschließend gegenüber dem Grenzgängerwesen positionieren. So wird hier das kulturell bereichernde Moment relativiert und von einer Sprachbedrohung durch Grenzgänger ausgegangen, was sich besonders im kleinbürgerlichen Milieu akzentuiert. Die Notwendigkeit der Grenzgänger/-innen wird jedoch bestätigt, ebenso wie - insbesondere im statusorientierten Milieu - die vermeintliche Arbeitsmarktkonkurrenz vergleichsweise niedrig bewertet wird.

Grenzgänger als vertraute Fremde: Die Aneignung der Grenzgänger/-innen als vertraute Fremde gibt den von Nassehi nicht vorgesehenen Umstand wieder, dass der Grenzgänger nach den betrachteten gesellschaftlichen Feldern sowohl ambivalent als auch eindeutig konstruiert wird. Dieser Status lässt sich an den Aneignungen der Luxemburger Wohnbevölkerung insgesamt und der Angehörigen des hedonistischen Milieus ablesen, welche das Grenzgängerwesen in sozio-kultureller Hinsicht positiv und negativ konstruieren. So gehen sie hier von einer kulturellen Bereicherung und von einer sprachlichen Bedrohung durch Grenzgänger/innen aus. Jedoch unterscheiden sich die genannten Gruppen hinsichtlich ihrer Konstruktionen auf sozio-ökonomischem Gebiet: Während die Luxemburger Wohnbevölkerung insgesamt die Unverzichtbarkeit der Grenzgänger/-innen für die Wirtschaft in einschließender Manier betont, unterstreichen hier die Hedonisten die Arbeitsplatzkonkurrenz, wodurch sie sich eher ausschließend positionieren. Der Status der Grenzgänger/-innen als vertraute Fremde lässt sich ebenso anhand der Aneignungsstrategien des traditionsorientierten Milieus bestimmen. Jedoch ist hier durch die Betonung der Arbeitsmarktkonkurrenz bei gleichzeitiger Notwendigkeit von Grenzgänger/-innen die Ambivalenz der Konstruktion auf sozio-ökonomischem Gebiet und die eher negativ-ausschließende Strategie auf sozio-kulturellem Gebiet auszumachen. 


\section{Zur Figur des (vertrauten) Fremden}

Die vorgenommene Analyse zeigt, dass die praktizierten Ein- und Ausschlussstrategien der Luxemburger Wohnbevölkerung verschiedene Aneignungsformen hinsichtlich des Grenzgängerwesens repräsentieren. Dabei überwiegt auf sozioökonomischem Gebiet tendenziell der Einschluss von Grenzgänger/-innen durch die Betonung ihrer wirtschaftlichen Unverzichtbarkeit. Hingegen werden in sozio-kultureller Hinsicht Ausschlussstrategien praktiziert, die vor allem auf das Bedrohungsmoment für die Luxemburger Sprache abheben. Diese Aneignungsprozesse, welche nach sozio-kulturellen Milieus variieren, wurden weiterführend auf Kohärenz geprüft, wodurch teilweise widersprüchliche Konstruktionen herausgearbeitet werden konnten. Diese unterscheiden sich je nach betrachtetem soziokulturellen Milieu und verweisen auf einen weitgehend ambivalenten Status der Grenzgänger/-innen in Luxemburg, der mit den Figuren des >Fremden< bzw. des >vertrauten Fremden< wiedergegeben wurde.

Dieser Befund erscheint angesichts der einleitenden Ausführungen zunächst als identitäres Dilemma, jedoch kann bei seiner Interpretation eine mögliche Logik des strategischen Zusammenspiels von alltagskulturellen Ein- und Ausschlüssen herausgearbeitet werden. Denn während im 20. Jahrhunderts die durch die Nachfrage der Unternehmen bedingte Präsenz von Immigranten/-innen und Grenzgängern/-innen »in den Köpfen zu einer Selbstverständlichkeit wurde« (vgl. Fehlen 2008: 82) und sich somit ausländerfeindliche Diskurse in Luxemburg kaum ausformten, etablierten sich besonders seit den Konjunkturumschwüngen nach der Jahrtausendwende protektionistische Strategien gegenüber der Konkurrenz ausländischer Arbeitskräfte. Diese kommen den Forschungsergebnissen folgend weniger in einer offenen und konsequenten Ablehnung von Grenzgänger/-innen im Sinne des >negativen Vertrauten $<$ zum Ausdruck, sondern ihnen wird aus den genannten Gründen durchaus ihre wirtschaftliche Unverzichtbarkeit zugebilligt. Jedoch endet diese aus Sicht vieler Luxemburger an der Schwelle zum staatlichen und halbstaatlichen Sektor, was über die erläuterte Verankerungskompetenz reguliert wird. Vor diesem Hintergrund erschließt sich die Logik des strategischen Zusammenspiels von sozio-ökonomisch motivierten Einschlussstrategien einerseits und von sozio-kulturell motivierten Ausschlussstrategien andererseits, die auf die Sicherung von Wachstum und Wohlstand im eigenen Land und auf den >Schutz< vor Arbeitsplatzkonkurrenz abstellt. Denn laut der Ergebnisse sind Grenzgänger/innen in den Augen der Wohnbevölkerung zwar wichtig für die Wirtschaft, ihr Zugang zur luxemburgischen Sprache könnte ihnen jedoch den Eintritt in die vor der Konkurrenz ausländischer Arbeitskräfte >geschützten< Sektoren weitgehend ermöglichen. So wird das sozio-kulturelle Argument der Sprachbedrohung - insbesondere im traditionsorientierten, unterprivilegierten und kleinbürgerlichen Milieu - in ausschließender Manier praktiziert, um den Wettbewerbsvorteil gegenüber Grenzgänger/-innen auf sozio-ökonomischem Gebiet zu sichern. 
Zunächst widersprüchlich erscheinende Aneignungsprozesse im Hinblick auf das Grenzgängerwesen können demnach durchaus >Logiken des Alltags< folgen, die dem Verlangen nach Sicherheit nachgeben und hierfür Gemeinschaft durch Abgrenzung imaginieren. Daher gilt es, sich den alltagskulturellen Aneignungen des Grenzgängerwesens, welches sich in Luxemburg sowohl der Kategorie des Vertrauten als auch der des Fremden entzieht, in ihrer Qualität des Zwischenkategorialen weiterführend zuzuwenden. Das bedeutet, die Aneignungen der Wohnbevölkerung explizit mit ihren Widersprüchen in den Blick zu nehmen und so den Grenzgänger als eine ambivalente aber dennoch eigenständige Kategorie zu rekonstruieren. Auf konzeptioneller Ebene impliziert dies eine Erweiterung des Ansatzes Nassehis durch die Denkfigur >vertrauter Fremder< [Vertrauter $(+/-) /$ Fremder]; auf empirischer Ebene gilt es, den Verortungen der Subjekte zwischen ein- und ausschließenden Aneignungsprozessen weiter nachzuspüren und somit der ambivalenten Logik des Alltagskulturellen auf die Spur zu kommen.

\subsection{Identitäten und Ambivalenzen des Alltagskulturellen}

Im vorliegenden Kapitel wurden verschiedene Bereiche des Alltagskulturellen exemplarisch beleuchtet und jeweils kursierende (politische) Zuschreibungen und/oder (individuelle sowie milieu-spezifische) Aneignungen in Bezug auf identitätskonstitutives Handeln aufgezeigt. Dabei ging es um Genderbilder und -erfahrungen, um Einstellungen zur Ernährung und um Wahrnehmungen der Grenzgänger/-innen in Luxemburg. Neben ihrer Alltagsrelevanz und ihrem identitätskonstitutiven Potential konnte eine weitere Gemeinsamkeit dieser Themen herausgearbeitet werden: eine ausgeprägte Ambivalenz. So werden in der betrachteten sozialen Praxis die Binaritäten männlich/weiblich, gut/schlecht und vertraut/fremd produktiv und z.T. arbiträr aufgebrochen, wodurch unterschiedliche >Logiken des Alltags< in Erscheinung treten.

Bei der Genderthematik bemerkenswert ist der Befund, dass die Befragten tendenziell nach dem Ideal der Gleichberechtigung handeln, gleichzeitig jedoch in ihren mentalen Haltungen (noch) traditionellen Mustern verhaftet bleiben. Diese Widersprüchlichkeit findet sich wieder in den Einstellungen zu Ernährungsfragen: >Gutes< Essen wird laut der Ergebnisse auf Zuschreibungsseite eher objektbezogen behandelt (etwa in Form von Ernährungsempfehlungen), während es auf Aneignungsseite eher personenbezogen gelebt wird (etwa in Form von Subjektivierung und Vergemeinschaftung). Dabei zeigen sich Praktiken, die zugeschriebene Identifikationsmerkmale gleichzeitig selektiv, kontextgebunden und permanent variierend integrieren (etwa in Form von Adaptation, Opposition oder Autonomie gegenüber Ernährungsempfehlungen). Grenzgänger/-innen schließlich werden den Befragten zufolge als wichtig für die wirtschaftliche Situation Luxemburgs angesehen, hingegen wird ihre in Alltagssituationen als unzureichend erlebte Luxemburgisch-Kompetenz kritisiert. Gleichzeitig steht dabei eher eine sprachlich zu 
realisierende Anerkennung des >Eigenen< im Vordergrund als die Sprachkompetenz als solche, insbesondere wenn es um die weitgehend von Luxemburgern dominierten und >geschützten< Bereiche des Arbeitsmarkts geht, über deren Zugang oftmals das Beherrschen des Luxemburgischen entscheidet.

In den hier untersuchten Fallbeispielen des Alltagskulturellen sind also Diskurspraktiken feststellbar, die eine binäre >Entweder-oder-Logik < pragmatisch überschreiten und sich in eine flexible >Sowohl-als-auch-Logik< einschreiben - so etwa, wenn im Geschlechter-Erleben sowohl Essentialismen als auch Konstruktivismen parallel praktiziert werden, wenn widersprüchliche Normen und Praxen sowohl von gesundem als auch von >sündhaftem< Essen sich wechselseitig durchdringen oder wenn Grenzgänger/-innen sowohl positiv als auch negativ - und somit als >vertraute Fremde< - wahrgenommen werden. Die latenten >Logiken des Alltags<, an denen sich dynamische Identitätskonstruktionen ablesen lassen, erscheinen somit im Luxemburger Untersuchungskontext weitgehend pragmatisch und selbstbezogen: ein Selbstverständnis der Subjekte, das Gender als nur einen Aspekt der Alltagspraxis unter vielen anderen erlebt und je nach Kontext naturalistisch oder kulturell argumentiert, das eine pragmatisch-hedonistische Ernährungspraxis im Alltag privilegiert oder ein Selbstverständnis, das dem Verlangen nach dem >Eigenen< durch ambivalente Konstruktionen des >Fremden< nachgibt.

Vor diesem Hintergrund ist festzuhalten, dass dieses Kapitel sich insbesondere mit angeeigneten Identitäten beschäftigt und zusätzlich untersucht hat, inwiefern zugeschriebene Identitäten (nicht) übernommen werden, wobei Strategien von Adaptation, Opposition und Autonomie hinsichtlich Identifikationsidealen wirken. Demnach sind Identitäten weder vorausbestimmt noch festgeschrieben, sondern sie können nur als Momentaufnahme und in der konkreten Alltagspraxis nachgezeichnet werden.

\subsection{LITERATURVERZEICHNIS}

\section{Primärquellen}

Ministère de la Santé/Ministère de l'Education Nationale et de la Formation Professionnelle/Ministère de la Famille et de l'Intégration/Département Ministériel des Sports (2007): Freude am gesunden Essen. Spaß an der Bewegung!/Le plaisir de bien manger et d'être actif!, Luxembourg.

\section{Sekundärquellen}

Allegrezza, Serge/Frising, Armande/Haag, Antoine/Langers, Jean/Reichmann, Liliane/ Schockmel, Marco (2007): »Egalité Hommes-Femmes. Mythe ou Réalité?«, in: Cahier Economique. No 105 du Statec, Luxembourg. 
Antoni-Komar, Irene/Pfriem, Reinhard/Raabe, Thorsten/Spiller Achim (Hg.) (2008): Ernährung, Kultur, Lebensqualität. Wege regionaler Nachhaltigkeit, Marburg: Metropolis.

Austin John (1962): How To Do Things with Words, Oxford: University Press.

Baltes-Löhr, Christel (2006): Migration und Identität. Portugiesische Frauen in Luxemburg. Frankfurt a.M./London: IKO-Verlag für Interkulturelle Kommunikation.

Baltes-Löhr, Christel (2009): »Umgang mit Differenzen«, in: Manuel Achten; Christel Baltes-Löhr et al. (Hg.): Maison Relais pour Enfants. Le Manuel - Das Handbuch, Luxembourg: Edition le Phare 2009, S. 88-117.

Barlösius, Eva (2008): »Weibliches und männliches rund ums Essen«, in: Alois Wierlacher/Regina Bendix (Hg.): Kulinaristik. Forschung, Lehre, Praxis, Berlin: Lit, S. 35-44.

Bhabha, Homi, K. (2000): Die Verortung der Kultur, Tübingen: Stauffenburg.

Bolten, Jürgen (2007): Einführung in die Interkulturelle Wirtschaftskommunikation. Stuttgart: UTB.

Bonz, Jochen/Struve, Karen: »Homi K. Bhabha: Auf der Innenseite kultureller Differenz: >in the middle of differnces««, in: Stephan Moebius, Dirk Quadflieg (Hg.): Kultur. Theorien der Gegenwart, Wiesbaden: VS, S. 140-153.

Bourdieu, Pierre (2000 [1972]): Esquisse d'une théorie de la pratique. Précédé de trois études d'ethnologie kabyle, Paris: Le Seuil.

Bourdieu, Pierre (1994): Raisons pratiques. Sur la théorie de l'action, Paris: Le Seuil.

Bourdieu, Pierre (1980): Le sens pratique, Paris: Editions de Minuit.

Bourdieu, Pierre (2000 [1972]): Esquisse d'une théorie de la pratique. Précédé de trois études d'ethnologie kabyle, Paris: Le Seuil.

Breinig, Helmbrecht/Lösch, Klaus (2006): »Transdifference«, in: Journal for the Study of British Culture 13/2, S. 105-122.

Bröckling, Ulrich/Krasmann, Susanne/Lemke, Thomas (Hg.) (2000): Gouvernementalität der Gegenwart. Studien zur Ökonomisierung des Sozialen, Frankfurt a.M.: Suhrkamp.

Brunner, Karl Michael/Geyer, Sonja/Jelenko, Marie/Weiss, Walpurga/Astleithner, Florentina (2007): Ernährungsalltag im Wandel. Chancen für Nachhaltigkeit, Wien/New York: Springer.

Brunnett, Regina (2009): Die Hegemonie symbolischer Gesundheit. Eine Studie zum Mehrwert von Gesundheit im Postfordismus, Bielefeld: transcript.

Butler, Judith (1993): Für ein sorgfältiges Lesen, in: Benhabib, Seyla et al. (Hg.): Der Streit um Differenz, Frankfurt a.M.: Fischer, S. 123-132.

Chambers, Iain (1996): Migration, Kultur, Identität, Tübingen: Stauffenburg.

Commission des Communautés Européennes (CE) (30.05.2007): Livre blanc. Une stratégie européenne pour les problèmes de santé liés à la nutrition, la surcharge pondérale et l'obésité, Bruxelles, COM (2007) 279 final, non publié au 
Journal Officiel. URL: http://europa.eu/legislation_summaries/public_health/ health_determinants_lifestyle/c11542c_fr.htm

Commission des Communautés Européennes (CE) (08.12.2005): Livre vert. Promouvoir une alimentation saine et l'activité physique. Une dimension européenne pour la prévention des surcharges pondérales, de l'obésité et des maladies chroniques, Bruxelles, COM (2005) 637 final, non publié au Journal Officiel. URL: http://europa.eu/legislation_summaries/public_health/health_ determinants_lifestyle/c11542b_fr.htm (15.01. 2010)

Corbeau, Jean-Pierre/Poulain, Jean-Pierre (2002): Penser l'alimentation. Entre imaginaire et rationalité, Paris: Privat.

Coveney, John (2006 [2000]): Food, Morals and Meaning. The Pleasure and Anxiety of Eating, London: Routledge.

Csergo, Julia (2009): Trop gros? L'obésité et ses représentations, Paris: Autrement.

Deleuze, Gilles (1968): Différence et Répétition, Paris: PUF.

Derrida, Jacques (1968): »La différance«, in: Bulletin de la Société Française de Philosophie 62.3., Paris, S. 73-120.

European Commission (2009): Scientific Report of the Mobility of Cross-Border Workers within the EU-27/EEA/EFTA Countries (Directorate General for Employment, Social Affaires and Equal Opportunities), Luxembourg.

Fehlen, Fernand (2008): »Streit um den roten Löwen. Diskurse über das nationale Selbstbild Luxemburgs im Spannungsfeld von Modernisierung und Rückwärtsgewandtheit«, in: Wilhelm Amann/Georg Mein et al. (Hg.): Periphere Zentren oder zentrale Peripherien? Kulturen und Regionen Europas zwischen Globalisierung und Regionalität, Heidelberg: Synchron Verlag, S. 61-87.

Fehlen, Fernand/Pigeron-Piroth, Isabelle (2009): Mondialisation du travail et pluralité des marchés du travail: L'exemple du Luxembourg, Diskussionsbeitrag der 12e Journées de Sociologie du Travail, 25. und 26. Juni 2009, GREE, Université de Nancy. URL: http://gree.univ-nancy2.fr/digitalAssets/53345_JIST_ Fehlen_Pigeron.pdf

Fischler, Claude (1990): L'homnivore. Le goût, la cuisine et le corps, Paris: Poches Odile Jacob.

Foucault, Michel (1993): »About the Beginnings of the Hermeneutics of the Self. Two Lectures at Dartmouth «, in: Political Theory, N²1/2, S. 198-227.

Foucault, Michel (1984a): Histoire de la sexualité, Tome 2: L'usage des plaisirs, Paris: Gallimard.

Foucault, Michel (1984b): „L'éthique du souci de soi comme pratique de la liberté«, in: Michel Foucault (1994): Dits et écrits. Tome 4: 1980-1988, Paris: Gallimard, S. 708-729.

Foucault, Michel (1983): »On the Genealogy of Ethics. An Overview of Work in Progress «, in: Paul Rabinow/Nicolas Rose (2003 [1994]), The Essential Foucault. Selections from the Essential Works of Foucault 1954-1984, New York/ London: The New Press, S. 102-125. 
Foucault, Michel (1982a): »The Subject and Power «, in: Paul Rabinow/Nicolas Rose (2003 [1994]): The Essential Foucault. Selections from the Essential Works of Foucault 1954-1984, New York/London: The New Press, S. 126-144.

Foucault, Michel (1982b): »Technologies of the Self«, in: Paul Rabinow/Nicolas Rose (2003 [1994]): The Essential Foucault. Selections from the Essential Works of Foucault 1954-1984, New York/London: The New Press, S. 145-169.

Foucault, Michel (1978): »La gouvernementalité. Séminaire au Collège de France en 1977 et 1978: Sécurité, territoire et population«, in: Aut-Aut, N 167-168, Paris: Gallimard, S. 12-29.

Foucault Michel (1969): L'archéologie du savoir, Paris: Gallimard.

Goffman, Erving (1969): Wir alle spielen Theater, München: Piper.

Gregory, Derek (1997): »Lacan and Geography. The Production of Space Revisted «, in: Georges Benko und Ulf Strohmayer (Hg.): Space and Social Theory. Interpreting Modernity and Postmodernity, Oxford: Blackwell Publishers, S. 203234 .

Hillmann, Karl-Heinz (2007): Wörterbuch der Soziologie, Stuttgart: Alfred Kröner.

Hirschauer, Stefan (2001): »Das Vergessen des Geschlechts. Zur Praxeologie einer Kategorie sozialer Ordnung«, in: Bettina Heinz (Hg.): Geschlechtersoziologie. Sonderheft der Kölner Zeitschrift für Soziologie und Sozialpsychologie, Opladen: Westdeutscher Verlag, S. 208-235.

Hörning, Karl H./Reuter, Julia (2004): »Doing Culture. Kultur als Praxis«, in: Dies. (Hg.): Doing Culture. Neue Positionen zum Verhältnis von Kultur und sozialer Praxis, Bielefeld: transcript, S. 9-15.

Jakobson, Roman (1971): »Signe zéro«, in: Ders.: Selected Writtings, II: Word and Language, Den Haag: Parin. S. 211-222.

Keupp, Heiner/Ahde, Thomas/Gmür, Wolfgang/Höfer, Renate/Mitzscherlich, Beate/Kraus, Wolfgang/Straus, Florian (2006): Identitätskonstruktionen. Das Patchwork der Identitäten in der Spätmoderne, Reinbek bei Hamburg: Rowohlt.

Klinger, Cornelia/Knapp, Gudrun-Axeli (2005): »Achsen der Ungleichheit - Achsen der Differenz - Verhältnisbestimmung von Klasse, Geschlecht, >Rasse</ Ethnizität«, in: Transit 5/2005.

Kreutzer, Florian/Roth, Silke (2006): Transnationale Karrieren. Biographien, Lebensführung und Mobilität, Wiesbaden: VS.

Kumoll, Karsten (2006): »Clifford Geertz: Die Ambivalenz kultureller Formen«, in: Stephan Moebius, Dirk Quadflieg (Hg.): Kultur. Theorien der Gegenwart. Wiesbaden: VS, S. 81-90.

Lamine, Claire (2008): Les intermittents du bio. Pour une sociologie pragmatique des choix alimentaires émergents, Paris: Editions de la Maison des Sciences de l'Homme \& Editions Quae.

Lüdi, Georges (2008): »Der Schweizer Sprachencocktail neu gemixt. Sprache als Brücke und Barriere«, in: Daniel Jentsch-Müller (Hg.): Die neue Zuwanderung. 
Die Schweiz zwischen Brain-Gain und Überfremdungsangst, Zürich: Avenir Suisse, S. 185-203.

Luxemburgisches Ministerium für Kultur, Hochschulbildung und Forschung (26.09.2008): 1. Fest der Grenzgänger - Grenzenlos feiern im Namen des interkulturellen Dialogs, Pressemeldung.

McCall, Leslie (2005): »Managing the Complexity of Intersectionality«, in: Signs (2005), 30(3), S. 1771-1800.

Ministère de l'Education Nationale et de la Formation Professionnelle/Ministère de la Santé/Universität Karlsruhe (2006): Gesundheit, motorische Leistungsfähigkeit und körperlich-sportliche Aktivität von Kindern und Jugendlichen in Luxemburg. Untersuchung für die Altersgruppen 9, 14 und 18 Jahre, Abschlussbericht zum Forschungsprojekt, Luxemburg.

Ministère de l'Education nationale et de la Formation professionnelle (2007): Les chiffres clés de l'éducation nationale 2005/2006. Statistiques et indicateurs, année scolaire 2005/2006, Luxembourg.

Ministère de l'Egalité des Chances (2006): Gleiche Rechte für Mädchen und Jungen, Frauen und Männer, Luxembourg.

Ministère de la Santé/Ministère de l'Education Nationale et de la Formation Professionnelle (2005a): Das Wohlbefinden der Jugendlichen in Luxemburg im internationalen Vergleich, Luxemburg.

Ministère de la Santé/Ministère de l'Education Nationale et de la Formation Professionnelle (2005b): Das Wohlbefinden der Jugendlichen in Luxemburg, 5. und 6. Klasse, Grundschule, Luxemburg.

Ministère de la Santé/Ministère de l'Education Nationale et de la Formation Professionnelle (2002): Das Wohlbefinden der Jugendlichen in Luxemburg, Luxemburg.

Nassehi, Armin (1995): »Der Fremde als Vertrauter. Soziologische Beobachtungen zur Konstruktion von Identitäten und Differenzen«, in: Kölner Zeitschrift für Soziologie und Sozialpsychologie 47, S. 443-463.

Park, Robert (1974): »Human Migration and the Marginal Man«, in: Collected Papers of Robert Ezra Park, Band 1, New York: Arno Press, S. 345-356.

Pries, Ludger (2008): Die Transnationalisierung der sozialen Welt, Frankfurt a.M.: Suhrkamp.

Poulain, Jean-Pierre (2002): Manger aujourd'hui. Attitudes, normes et pratiques, Paris: Privat.

Reckinger, Rachel (2008): Les pratiques discursives oenophiles entre normativité et appropriation. Contribution à une sociologie des cultures alimentaires, 2 tomes, thèse de doctorat en sociologie, Marseille: Ecole des Hautes Etudes en Sciences Sociales.

Rose, Nicolas (1999 [1989]): Governing the Soul. The Shaping of the Private Self, London: Free Association Books.

Reckwitz, Andreas (2004): »Die Kontingenzperspektive von Kultur. Kulturbegriffe, Kulturtheorien und das kulturwissenschaftliche Forschungsprogramm«, in: 
Friedrich Jaeger/Jörn Rüsen (Hg.): Handbuch der Kulturwissenschaften. Themen und Tendenzen, Stuttgart: Metzler, S. 1-20.

Reckwitz, Andreas (2001): »Multikulturalismustheorien und der Kulturbegriff: Vom Homogenitätsmodell zum Modell kultureller Interferenzen«, in: Berliner Journal für Soziologie, Heft 2, Jg. 11, S. 179-200.

Reuter, Julia/Wiesner, Matthias (2008): »Soziologie im Zwischenraum: Grenzen einer transdifferenten Perspektive«, in: Lars Allolio-Näcke/Britta Kalscheuer (Hg.): Kulturelle Differenzen begreifen. Das Konzept der Transdifferenz aus interdisziplinärer Sicht, Frankfurt a.M.: Campus, S. 129-143.

Reuter, Julia (2002): Ordnungen des Anderen. Zum Problem des Eigenen in der Soziologie des Fremden, Bielefeld: transcript.

Rölli, Marc (2006): »Gilles Deleuze: Kultur und Gegenkultur«, in: Stephan Moebius, Dirk Quadflieg (Hg.): Kultur. Theorien der Gegenwart, Wiesbaden: VS, S. 30-41.

Rutherford, Jonathan (1990): »The Third Space. Interview with Homi Bhabha«, in: Ders. (Hg.): Identity: Community, Culture, Difference, London: Lawrence and Wishart: 207-221.

Scholliers, Peter (Hg.) (2001): Food, Drink and Identity. Cooking, Eating and Drinking in Europe since the Middle Ages, Oxford/New York: Berg.

Schütz, Alfred (1972): Gesammelte Aufsätze. Band 2: Studien zur soziologischen Theorie, hg. von Arvid Brodersen, Den Haag: Nijhoff.

Schütz, Alfred (1971): »Der Fremde. Ein sozialpsychologischer Versuch«, in: Ders.: Gesammelte Aufsätze, Band 2, Den Haag: Martinus Nijhof, S. 53-69.

Simmel, Georg (1908): Soziologie. Untersuchungen über die Formen der Vergesellschaftung, Duncker \& Humblot: Berlin.

Ståhl, Timo/Wismar, Matthias/Ollila, Eeva/Lahtinen, Eero/Leppo, Kimmo (Hg.) (2006): Health in All Policies. Prospects and Potentials, Ministry of Social Affairs and Health, Finland \& European Observatory on Health Systems and Policies. URL: www.euro.who.int/document/E89260.pdf (15.01. 2010)

STATEC (2009a): L'économie luxembourgeoise. Un kaléidoscope 2008, Luxembourg.

STATEC (2009b): Le secteur public. Economie et Statistiques, Working papers du STATEC 34.

Stichweh, Rudolf (2005): Inklusion und Exklusion. Studien zur Gesellschaftstheorie, Bielefeld: transcript.

Wagener, Yolande (2008): »Promotion de la santé au Luxembourg«, in: Promotion \& Education, Hors-Série Promotion de la santé: Besoin de recherche francophone et perspectives, $\mathrm{N}^{\circ}$ 1, S. 22-25.

Weischer, Christoph (2007): Sozialforschung, Weinheim: Beltz.

Welsch, Wolfgang (2005): »Auf dem Weg zu transkulturellen Gesellschaften«, in: Lars Allolio-Näcke/Britta Kalscheuer/Arne Manzeschke (Hg.): Differenzen anders denken. Bausteine zu einer Kulturtheorie der Transdifferenz, Frankfurt a.M.: Campus, S. 314-341. 
World Health Organisation Europe (WHO) (1999): Santé 21. La politique-cadre de la Santé pour tous dans la Région européenne de l'OMS. Série européenne de la Santé pour tous, $\mathrm{N}^{\circ} 6$.

World Health Organisation Europe (WHO) (2008): Inequalities in Young People's Health. Health Behaviour in School-Aged Children (HBSC). International Report from the 2005/2006 Survey. Health policy for children and adolescents, $\mathrm{N}^{\circ} 5$. 


\section{Aus:}

Politiques, Sociétés, Espaces IPSE - Identités (Hg.)

Doing Identity in Luxemburg

Subjektive Aneignungen - institutionelle Zuschreibungen sozio-kulturelle Milieus

Juli 20I0, 304 Seiten, kart., zahlr. z.T. farb. Abb., 29,80€, ISBN 978-3-8376-I448-o

Luxemburg - internationaler Finanzplatz, europäisches Verwaltungszentrum, Einwanderungsland?

Dieses Buch gibt Einblicke in eine wenig erforschte Gesellschaft und Hinweise auf Identitätskonstruktionen unter globalisierten Bedingungen. Das interdisziplinäre Autorenteam arbeitet subjektive Aneignungs- und institutionelle Zuschreibungsprozesse auf den Gebieten »Sprache«, »Raum«, »Alltagskultur« sowie »Selbst-« und »Fremdbild« heraus und ermittelt erstmals sozio-kulturelle Milieus im Großherzogtum. Der materialreiche Band zeigt Ambivalenzen und Dynamiken in einer multikulturellen und mehrsprachigen Gesellschaft auf.

In der Forschungseinheit IPSE (Identités, Politiques, Sociétés, Espaces) an der Universität Luxemburg arbeiten Wissenschaftler/-innen zu gesellschaftsrelevanten Fragen.

Weitere Informationen und Bestellung unter:

www.transcript-verlag.de/tsi448/tsi448.php

(C) 20I0 transcript Verlag, Bielefeld 


\section{Inhalt}

\section{Vorwort}

Rachel Reckinger, Christian Schulz, Christian Wille | 7

\section{Identitätskonstruktionen erforschen}

Rachel Reckinger und Christian Wille | 11

\section{Sozio-kulturelle Milieus in Luxemburg}

Wilhelm Amann, Fernand Fehlen, Georg Mein $\mid 37$

\section{Sprachen und Identitäten}

Peter Gilles, Sebastian Seela, Heinz Sieburg, Melanie Wagner | 63

\section{Räume und Identitäten}

Marion Colas-Blaise, Sylvie Freyermuth, Sonja Kmec, Gian Maria Tore,

Christian Schulz | 105

\section{Bilder und Identitäten}

Wilhelm Amann, Viviane Bourg, Paul Dell, Fabienne Lentz, Paul Di Felice, Sebastian Reddeker $\mid 165$

\section{Alltagskulturen und Identitäten}

Christel Baltes-Löhr, Agnes Prüm, Rachel Reckinger, Christian Wille | 235

\section{Identitätskonstruktionen in Luxemburg}

Rachel Reckinger, Christian Schulz, Christian Wille | 295

Autoren | 299 